\title{
Group Spatial Preferences of Residential Locations-Simplified Method Based on Crowdsourced Spatial Data and MCDA
}

\author{
Joanna Jaroszewicz *(D) and Anna Majewska \\ Department of Spatial Planning and Environmental Sciences, Warsaw University of Technology, \\ 00-661 Warsaw, Poland; anna.majewska@pw.edu.pl \\ * Correspondence: joanna.jaroszewicz@pw.edu.pl
}

check for

updates

Citation: Jaroszewicz, J.; Majewska, A. Group Spatial Preferences of Residential Locations-Simplified Method Based on Crowdsourced Spatial Data and MCDA.

Sustainability 2021, 13, 4690. https:// doi.org/10.3390/su13094690

Received: 29 March 2021

Accepted: 20 April 2021

Published: 22 April 2021

Publisher's Note: MDPI stays neutral with regard to jurisdictional claims in published maps and institutional affiliations.

Copyright: (c) 2021 by the authors. Licensee MDPI, Basel, Switzerland. This article is an open access article distributed under the terms and conditions of the Creative Commons Attribution (CC BY) license (https:// creativecommons.org/licenses/by/ $4.0 /)$.

\begin{abstract}
Residential location preferences illustrate how the attractiveness of particular neighbourhoods is perceived and indicate what improves or lowers the comfort of life in a city according to its residents. This research analyses the residential preferences of students who were asked to indicate their most preferred residential locations and to define their selection criteria. The study was conducted in two phases: in 2019, before the outbreak of the pandemic, and in 2020 during the second wave of the COVID-19 outbreak. The methodology of spatial multi-criteria analyses and the developed simplified approach to determining collective preferences from crowdsourced data FCPR (first criteria partial ranking) were used to analyse the preferences. The following research questions were asked: (1) whether the developed simplified FCPR methodology would provide results similar to the methods currently used to determine group weightings of criteria; (2) what spatial aspects were important for the students when choosing where to live, and (3) whether these aspects change in the face of the pandemic. The results obtained confirmed the effectiveness of the simplified approach. They indicated a significant relationship between an efficient public transport system and residence preferences, even with prolonged distance learning. They also showed the increased importance of location close to family or friends in the face of the pandemic. Only a combined analysis of the preferences expressed both in the form of a ranking of criteria and directly indicated locations provides complete information.
\end{abstract}

Keywords: residential preferences; multi-criteria analysis; COVID-19; urban attractiveness; group weights; Borda count; stated preferences; revealed preferences; GIS

\section{Introduction}

The idea of a sustainable city as a good place to live, taking into account the social, cultural, economic and environmental dimensions, has been under development since the 1980s [1,2]. In the new generation of smart cities 3.0, instead of economic growth rates, it is general feelings of happiness, contentment and acceptance that are considered most important. This means that cities should develop based on the potential of citizens [3] who love the cities they live in [4]. The attractiveness of a place of residence is influenced by many factors, such as harmoniously shaped spatial arrangements and the availability of safe public spaces [5], proper relations between the typology of buildings and the morphology of the urban space [6], access to green areas, the availability of necessary service infrastructure and a system of bicycle and pedestrian paths [7], biodiversity and climate resilience and ecosystem services, including access to clean water (filtration) and clean air (urban greenery) [8]. The pandemic has revealed the resilience of the urban system [9] to risks arising from poor hygiene and sanitary conditions, inappropriate distribution of services [10] and growing social inequalities [11]. The COVID-19 pandemic has triggered a process of changes in behaviour and social habits, especially those related to the use of urban spaces and transport $[12,13]$. Links are shown between the development of the pandemic and the mental and physical health of the residents, as well as the associated 
vitality of the city [14,15], which is heavily influenced by available green spaces [16-21]. The importance of the immediate neighbourhood is also increasing [22,23], both in the social dimension, providing the opportunity to obtain assistance and a sense of security, as well as in the functional-spatial dimension, allowing the reduction of pollution and noise, through having smaller distances and mixed use design [24,25].

The research concerns the preferences of potential residents in choosing a place to live within large cities, as regards good living conditions and sustainable development. Large cities are often important academic centres, so the focus was on a group of students-young people facing the choice of where to live in the near future. Students are both residents and visitors of these cities, living there temporarily. Many of them choose to stay in the city after graduation, as it offers attractive employment opportunities, cultural attractions and recreational opportunities. During their studies, students are accommodated in student hostels, they rent rooms or flats in the city, they live with family or, less frequently, they have their own accommodation. Residential preferences are a complex and sometimes inconsistent set of different factors [26,27]. Sustainable urban planning increasingly uses information about the residents' perceptions of factors affecting the quality of life in certain locations [4]. Residential preferences play an important role in the sustainable development of cities. This issue has been the subject of many studies in recent years. Various methodological approaches have been used, including statistically evaluated surveys, e.g., [28-31] as well as geo-questionnaires and geo-crowdsourced data, e.g., [32-35]. Location preferences can be expressed both by specifying location selection criteria and their importance, as well as directly by identifying the best locations. Multi-criteria decision analysis in geographic information systems (GIS-MCDA) is a collection of methods providing opportunities to carry out a combined analysis of these two types of information. It also makes it possible to set common preferences representing a group of people.

GIS-MCDA allows both spatial (geographical) data and data about the participants' (the decision-makers') preferences to be processed and analysed in order to obtain information supporting spatial planning and decision-making processes [36]. In the group of multi-criteria methods based on value/utility function [37], the process of multi-criteria analysis in geographical information systems generally includes the following steps [38]: formulating the decision problem, defining the criteria, mapping the criteria values, evaluating and standardising criteria values, determining the significance weightings for the criteria, applying the aggregation function (combination rule), and carrying out a sensitivity analysis. The analysis results in a ranking of decision alternatives. Based on this, proposals are formulated for taking specific actions in the geographical space. In the traditional MCDA approach, the decision-maker's preferences for decision alternatives, e.g., the most preferred locations, are not indicated ad hoc, but are the result of an analysis in which the assessment of the relative importance of criteria, expressed in terms of criteria weights (stated preferences), plays a key role. In a geo-questionnaire concerning housing preferences, these preferences are expressed both explicitly (stated preferences) through the questions themselves, and by directly indicating preferred locations-from which conclusions on revealed preferences can then be drawn [39]. In addition, in the currently developing spatial decision support systems (SDSS) incorporating crowdsourced data, the preferences can be determined both as stated preferences (determining the relevance of criteria) and as revealed preferences derived from indicated locations or geographical features [40].

The decision-maker's preference for the criteria is expressed through the weights of relative significance of the criteria. In most methods, the weights: $w_{j}(j=1,2, \ldots, n)$ meet two assumptions: they take values between 0 and 1 and add up to 1 [36-38]. Depending on the applied MCDA method and aggregate function, the criteria weights have different interpretations and implications [41,42].

Objective vs. subjective weights. Objective and/or subjective reasons are taken into account to determine the weights. This may lead to different results [43]. The objective reasons are related to the differentiation of criteria values across individual decision al- 
ternatives. This is encapsulated in the range-sensitive principle $[36,37,44]$. The lower the variation, the lower the significance of the criterion. The differentiation of a criterion value may be expressed in a number of ways, such as the range of values of the criterion [45-47], entropy [48,49] or standard deviation (SD) [50]. The subjective reasons for determining weights refer to the decision-maker's subjective perceptions and judgements about the relative importance of the criteria. In GIS-MCDA, the most commonly used subjective methods for determining weights are ranking and pairwise comparison matrix (PCM) [51].

Global vs. local weightings. Locally determined corrections based on objective reasons can be used to override global weights determined subjectively by a decisionmaker [36]. These corrections may be based on the local ranges of values [52,53] or the locally determined value of entropy [36]. This is how spatially explicit weights (local weights) are acquired. Another approach is to vary the values of the weights based on the distance relationship to the selected geographic features [54]. Spatially explicit MCDA advancement is a major trend in GIS-MCDA development [40].

Statistical revealed weights. The values of weights can be determined in the decisionmaking process from decisions made currently or in the past. Statistical methods are then used. Korhonen et al. [55] demonstrated in a simple two-criterion experiment that, based on the pairwise comparisons of decision alternatives, the weights that best explain those pairwise comparisons can be determined using statistical methods to a greater extent than the subjective weights given by the decision-makers. In this way, on the basis of the decisions made, it is possible to attempt to know the preferences of the decision-maker regarding the criteria. Veronesi et al. [56] employed a statistical analysis to quantitatively calculate weights and tested their method on a case study about siting a transmission line in Switzerland. They compared the criteria values at the locations of the current transmission siting with the values at the locations of randomly generated points. The greater the difference in value, the higher the weight that the criterion received as a result.

Group criteria weights. Group decision-making occurs when many decision-makers are involved in the decision process [57]. Several levels of Group GIS-MCDA can be distinguished, depending on whether stakeholders, invited participants or the entire community are involved in the decision-making process (social multi-criteria evaluation) [58]. The structure of the decision problem may vary depending on whether or not an external consensus has been reached on the main elements of the decision-making process, including the value of the criteria weights [59]. With the development of new technologies such as Public Participation GIS (PPGIS) and geo-questionnaires techniques, opportunities have arisen to involve an increasing number of decision-makers in the decision-making process $[34,40]$. Methods of incorporating crowdsourced data into GIS-MCDA have begun to develop intensively. Jelokhani-Niaraki [60] recently conducted a comprehensive and systematic review of peer-reviewed studies and determined the direction of research involving state-of-the-art collaborative GIS-MCDA tasks and tools. The meta-analysis of previous collaborative GIS-MCDA conducted indicated that $46 \%$ of the items were related to the issue of determining the weights of the significance of the criteria. The correct weighting of criteria by non-expert decision-makers can be problematic [61,62]. To solve this problem, complex decision support systems can be used that involve additional information for specifying weights, enabling information exchange and leading to collaboration between decision-makers $[63,64]$. Another approach might be to simplify the process of determining weights as much as possible-which is proposed in this article.

Stated vs. revealed criteria weights based on crowdsourced preference data. The crowdsourced data can be used both to extract geographic data, to create criteria maps based on them and to determine the preferences of decision-makers (CPD—crowdsourced preference data), where CPD preferences can take the form of stated preferences (SP) or revealed preferences (RP). Stated preferences (SP) take the form of criteria weights or are expressed through rankings [40]. Once each participant has determined their preferences independently by determining the criteria weights or ranking of criteria, further analysis can continue in parallel, so that, after individual results have been obtained, they are aggre- 
gated into a group result that is representative of the majority of the decision-makers $[59,65]$. Alternatively, based on individually determined pairwise comparison matrices (PCMs) or criteria rankings, common criteria weights can be calculated that are representative of the collective decision-maker [64]. For revealed preferences (RP), decision-makers indicate locations and criteria preferences that are implicit in the decision-making process. They are then guided in their decision making by the holistic synthesis of information [66]. Mahmoody Vanolya et al. [67] conducted the validation of GIS-MCDA results using PPGIS based on a performed case study on locating suitable areas for a new restaurant. They compared the results obtained by experts, who expressed their stated preferences as criteria weights, against the revealed preferences of citizens, given by indicating locations on a map using PPGIS. The validation results indicated a low level of consistency between the experts' solutions and the citizens' opinions. This issue was also raised in the context of studies on choices about the form of transport [68]. Hasanzadeh et al. [27] evaluated the consistency of the preferred housing environment of participants (stated preferences) with their actual living environment (revealed preferences). The results they obtained showed a considerable lack of consistency. It is interesting in the context of the spatial analyses to see whether the results obtained from stated preferences and revealed preferences are consistent if they are set by the same group of participants and, in both cases, refer to a preferred state.

This paper uses an approach in which group preferences-representing the whole group-are determined based on the housing preferences of individual participants of a geo-questionnaire. The method suggested for this purpose allows group preferences to be determined on the basis of a simplified vote on the ranking of criteria. In this method, respondents indicate only the order of the $k$ first criteria. This method is defined as FCPR (First Criteria Partial Ranking). In this way, group-stated preferences were determined. In addition, the participants indicated their most preferred locations (revealed preferences). The decision-makers' preferences regarding the relevance of criteria and, consequently, their objectives in making the choice [37] may change over time. In determining group preferences, such a change will illustrate the direction of change of the group as a whole. The paper asks the following questions: (1) will the proposed simplified first criteria partial ranking method (FCPR) of voting for $k$ first criteria ranking produce common weights consistent with the common weights obtained by the traditionally used methods: ranking and the pairwise comparison method (PCM)? (2) Will the stated preferences indicated by respondents be consistent with the revealed preferences expressed by indications of location? (3) Will rapid changes in the global situation, such as the outbreak of the COVID19 pandemic, affect group housing preferences?

In order to answer these questions, a simple geo-questionnaire was carried out analysing preferences regarding the location of residence of students at the Faculty of Geodesy and Cartography of the Warsaw University of Technology. Using a simple Google form, students defined their stated preferences (SP) by indicating the criteria they considered most important. They also indicated their preferred locations (revealed preferences, $\mathrm{RP}$ ). The geographical coordinates B and L were entered into the Google form (coordinates system WGS84, EPSG: 4326) of indicated preferred locations in the map service of the City of Warsaw (mapa.um.warszawa.pl; accessed on 21 April 2021). The results of research carried out in 2019, when no one anticipated a pandemic, were used. They were a continuation of research aimed at examining the spatial housing preferences of students. After the outbreak of the pandemic, research using the same simple geo-questionnaire and procedures was carried out again. This allowed us to track changes in the obtained results. Housing preferences, understood as preferred locations, show the students' view of the city and the attractiveness of particular neighbourhoods. At the same time, they indicate what, from the students' point of view, most influences the comfort of living in the city. In the study, they were asked to forget for a moment about their own budgets, to identify their dream locations and choose the criteria that guided them in their selection. The study was conducted in two phases: in 2019-before the outbreak of the pandemic, and 
in autumn 2020-during the second wave of the COVID-19 epidemic in Poland. We used the methodology of spatial multi-criteria analyses (GIS-MCDA) and the developed FCPR method to analyse the indicated preferences. In addition, a smaller group of participants (the control group) underwent additional tests in order to obtain the values of the criteria weights using methods based on the full ranking and the pairwise comparison method (PCM). This allowed us to evaluate the results obtained using the FCPR method and to select the best technique for approximating the values of the weights.

\section{Materials and Methods}

In two time periods, DATE(1) and DATE(2), a simple geo-questionnaire on housing preferences was carried out, in which students at the Faculty of Geodesy and Cartography of the Warsaw University of Technology determined the relevance of the criteria for choosing the preferred location (SP) and indicated the selected locations (RP). In the current research, SPs were obtained using the developed FCPR method, in which respondents indicate $k$ of the most important criteria from a set of $n$ criteria. During the DATE(2) period, studies were also conducted in the control group. The general scheme of the analysis is shown in Figure 1. In the control group, the respondents identified criteria preferences using the criteria ranking and the pairwise comparison method (PCM). From these results, the voting results for the $k$-first ranking positions used in the FCPR method were also generated. Based on the collected data, group weights of the criteria were determined using various approximation techniques (RS, RR and CA). The similarity in the resulting sets of criteria weights was then assessed. Based on this, the best approximation technique was selected for determining the weights using the FCPR method. This technique was used further to derive criteria weights based on the results of the geo-questionnaires conducted over the two time periods. The results were compared between DATE(1) and DATE(2). Finally, the results based on stated preferences were compared with the indicated locations (revealed preferences).

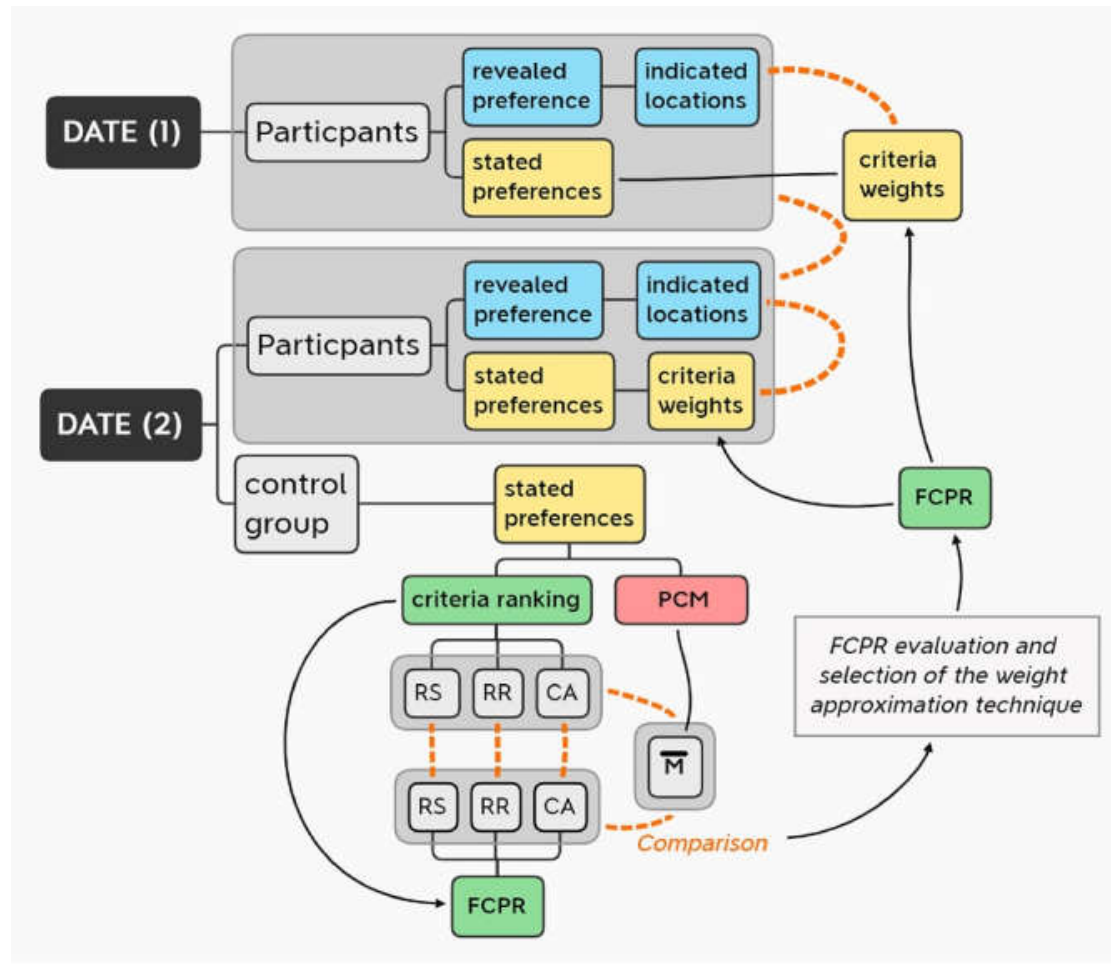

Figure 1. General scheme of the analyses carried out and comparisons of the results. 


\subsection{Common Weights of the Criteria Determined by the Pairwise Comparison Matrix Method}

In the pairwise comparison method (PCM), introduced by Saaty in the 1980s to the analytic hierarchy process (AHP) that he developed [69], significance comparisons are made between pairs of criteria. The set of all such judgements is represented by a square matrix M:

$$
\mathbf{M}=\left[p c_{i j}\right]_{n \times n^{\prime}}
$$

where $p c_{i j}$ is a pairwise comparison of the $i$-th criterion with $j$-th criterion.

To record the assessment of pairwise comparisons, a numerical scale with values from 1 to 9 is used, where 1 is a pair of criteria of equal significance and 9 is the extreme dominance of the first criterion of the pair over the second one [69]. For example, if criterion $A$ is three times more important than criterion $B$, then the element of the matrix is $p c_{A B}=3$, while the element of $p c_{B A}=1 / 3$. The extreme values, i.e., $7,8,9$ or $1 / 7,1 / 8,1 / 9$, are used where dominance is evident in practice or supported by evidence [70]. The values of the weights form a certain vector $\mathbf{w}=\left[w_{1}, w_{2}, \ldots, w_{n}\right]$, which is a unique solution to the equation: $\mathbf{M w}=\lambda_{\max } \mathbf{w}$, where $\lambda_{\max }$ is the largest unique eigenvalue of matrix $\mathbf{M}$. One of the methods for approximating the values of the criteria weights is the averaging procedure in standardised columns [69]. At the first stage of the procedure, the values of the pairwise comparisons $p c_{i j}$ are standardised in each column of matrix $\mathbf{M}$ :

$$
p_{i j}=\frac{p c_{i j}}{\sum_{i=1}^{n} p c_{i j}}, \text { for } j=1,2, \ldots, n \text { columns, }
$$

then the weights are determined as arithmetic means of the values $p_{i j}$ in matrix rows:

$$
w_{i}=\frac{\sum_{j=1}^{n} p_{i j}}{n}, \text { for } i=1,2, \ldots, n \text { rows. }
$$

The assigned weights should satisfy the consistency condition where consistency ratio $C R<0.10$, while $C R$ is defined as follows [69]:

$$
C R=\frac{\lambda_{\max }-n}{R I(n-1)}
$$

where $\lambda_{\max }$ is the largest eigenvalue of matrix $\mathbf{M}, R I$ is the random index, namely the consistency ratio of the randomly generated pairwise comparison matrix. The value of the random index $R I$ depends on the number of criteria [71].

On the basis of the pairwise comparison matrix $\mathbf{M}$ obtained from the individual decision-maker (DM), an averaged common matrix may be determined M. This becomes the basis for calculating common weights of criteria representing the preferences of a group of decision-makers (groupDM). Elements of the matrix $\mathbf{M}$ are calculated as geometric averages of the corresponding elements of the individual matrices [72]:

$$
\overline{p_{i j}}=\sqrt[z]{\prod_{g=1}^{z} p_{i j_{g^{\prime}}}}
$$

where $g=1,2, \ldots, z$ mean consecutive decision-makers ( $D M g$ ) participating in the geoquestionnaire. The common weights for the group of decision-makers are then calculated from the averaged matrix $\mathbf{M}$.

\subsection{Common Weights of the Criteria Determined on the Basis of the Ranking Method}

For the ranking of criteria, when numerical weights are assigned to each criterion based on rank order, surrogate weights can then be derived [62]. There are some weighting 
approximation techniques based on the ranking of criteria, for example rank sum weights $\left(R S w_{j}\right)$ or rank reciprocal weights $\left(R R w_{j}\right)[73]$ :

$$
\begin{gathered}
R S w_{j}=\frac{n+1-r_{j}}{\sum_{j=1}^{n}\left(n+1-r_{j}\right)}, \\
R R w_{j}=\frac{1 / r_{j}}{\sum_{j=1}^{n}\left(1 / r_{j}\right)},
\end{gathered}
$$

where $w_{j}$ is the weight of the $j$-th criterion, $n$ is the number of criteria $(j=1,2, \ldots, n)$, and $r_{j}$ is the rank of the $j$-th criterion with 1 representing the most important criterion. Danielson and Ekenberg [74] also used the additive combination of $R S w_{j}$ and $R R w_{j}$ :

$$
A C w_{j}=\frac{\frac{1}{r_{j}}+\frac{n+1-r_{j}}{n}}{\sum_{j=1}^{n}\left(\frac{1}{r_{j}}+\frac{n+1-r_{j}}{n}\right)},
$$

Based on the criteria weights obtained from the individual rankings, the common criteria weights can be determined using the expected value algorithm [75], or using the Borda method of ranking votes [76,77] after the calculation of the points resulting from the adopted weights approximation techniques. In this second approach, based on the ranking order determined by each decision-maker $D M_{g}$ (for $g=1,2, \ldots, z$ ), points are given for each $j$-th criterion. Assuming these three weights' approximation techniques based on the ranking of criteria: RS, RR and AC (described respectively by Equations (6)-(8)), points may be awarded as follows:

$$
\begin{gathered}
P_{j}^{g}=n+1-r_{j}^{g}, \text { for the RS technique } \\
P_{j}^{g}=1 / r_{j}^{g}, \text { for the RR technique } \\
P_{j}^{g}=\frac{1}{r_{j}^{g}}+\frac{n+1-r_{j}^{g}}{n}, \text { for the AC technique }
\end{gathered}
$$

where $r_{j}^{g}$ describes the position of the $j$-th criterion in the ranking made by the $g$-th decisionmaker and $n$ is the number of criteria. The number of points given to a certain $j$-th criterion by all decision-makers: $\sum_{g=1}^{z} P_{j}^{g}$ determines the position of this criterion in the final joint ranking. Since this is a situation in which a certain $j$-th criterion can be placed in the same ranking position by multiple decision-makers, it can be assumed that:

$$
\sum_{g=1}^{z} P_{j}^{g}=\sum_{r=1}^{n}\left(P_{r} \cdot N_{r j}\right), \text { for each } j=1,2, \ldots, n \text { criterion, }
$$

where $N_{r j}$ is the number of decision-makers who indicated the $j$-th criterion in $r$ position in the ranking, while $P_{r}$ is the number of points granted for the criterion located in $r$ position on the ranking, depending on the RS, RR or AC technique:

$$
\begin{gathered}
P_{r}=n+1-r, \text { for the RS technique, } \\
P_{r}=1 / r, \text { for the RR technique, } \\
P_{r}=\frac{1}{r}+\frac{n+1-r}{n}, \text { for the AC technique. }
\end{gathered}
$$

In that case, the sum of points awarded to the $j$-th criterion can be written as:

$$
\operatorname{SUM}\left(P_{j}\right)=\sum_{r=1}^{n}\left(P_{r} \cdot N_{r j}\right)
$$


Based on the final score thus determined, the criteria weights can be calculated as:

$$
w_{j}=\frac{\operatorname{SUM}\left(P_{j}\right)}{\sum_{j=1}^{n} \operatorname{SUM}\left(P_{j}\right)},
$$

Both the pairwise comparison matrix (PCM) and ranked-choice voting methods require considerable effort on the part of the respondents. The proposed simplified method of ranking only the $k$ most important criteria (FCPR) allows the group weights of criteria to be determined more easily.

\subsection{First Criteria Partial Ranking (FCPR)}

To simplify the voting procedure, a different method of voting is proposed, namely the first criteria partial ranking (FCPR), where decision-makers indicate the positions of only the $k$ most important criteria, while: $k<n$ (see: Figure 2).

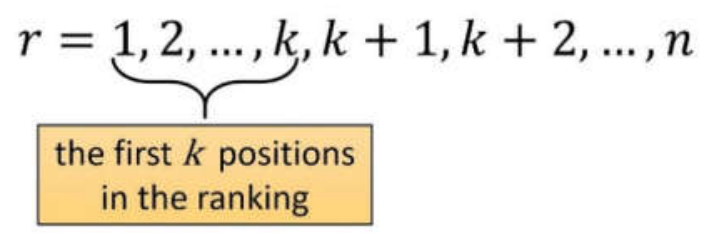

Figure 2. Idea of first criteria partial ranking (FCPR).

The FCPR method means that each decision-maker $D M_{g}($ where $g=1,2, \ldots, z)$ describes the ranking for the $k$ most important criteria $(k<n)$, determining their position in the ranking $r_{j \subset k}=1,2, \ldots, k$ For the other criteria, the DM does not determine the ranking position. For position: $r=1,2, \ldots, k$, the following points are granted:

$$
\begin{gathered}
P_{r}=n+1-r \text { for the RS technique, } \\
P_{r}=1 / r \text { for the RR technique, } \\
P_{r}=\frac{1}{r}+\frac{n+1-r}{n} \text { for the AC technique. }
\end{gathered}
$$

Criteria outside the first $k$ positions in the ranking will be awarded an equal value of points, denoted here as $P_{0}$, which can be calculated as follows:

for the RS technique:

$$
P_{0}=\frac{\sum_{r=k+1}^{n}(n+1-r)}{n-k}
$$

for the RR technique:

$$
P_{0}=\left(\prod_{r=k+1}^{n} \frac{1}{r}\right)^{\frac{1}{(n-k)}}
$$

for the AC technique:

$$
P_{0}=\frac{\sum_{r=k+1}^{n}(n+1-r)}{n(n-k)}+\left(\prod_{r=k+1}^{n} \frac{1}{r}\right)^{\frac{1}{(n-k)}}
$$

Finally, the total score for the $j$-th criterion is determined as follows:

$$
\operatorname{SUM}\left(P_{j}\right)=\sum_{r=1}^{k}\left(P_{r} \cdot N_{r j}\right)+P_{0} N_{0 j}
$$

After calculating the sum points, the weights of the criteria are determined according to Equation (13). 


\subsection{Comparison of the Weights Determined Using Different Methods and Techniques}

Criteria weights calculated using the ranking method and the FCPR method, with points awarded using three approximation techniques, namely RS, RR and AC, and weights

obtained from the averaged matrix of pairwise comparisons $\mathbf{M}$ using the PCM method, therefore together creating a collection of seven sets of group criteria weights. The values of the weights between the sets were compared using the squared distance norm:

$$
C=\sqrt{\sum_{j=1}^{n} \Delta_{(I-I I)}^{2}}
$$

where $\Delta_{(I-I I)}$ is the weights difference of a certain $j$-th criterion: $\Delta_{(I-I I)}=w_{j}(I)-w_{j}(I I)$, while $w_{j}(I), w_{j}(I I)$ are the weights of this criterion in the two sets of weights being compared. On the other hand, the similarity between the obtained rankings of the criteria was assessed by using rank correlation coefficients [78]: $r_{S}$, Spearman's rank correlation coefficient [79], and WS rank similarity coefficient introduced by Sałabun and Urbaniak [80], where changes in the ranks at the top of the ranking have more influence on the coefficient [78]:

$$
\begin{gathered}
r_{S}=1-\frac{6 \sum_{j=1}^{n} d_{j}^{2}}{n\left(n^{2}-1\right)}, d_{j}=R_{(I)_{j}}-R_{(I I)_{j}} \\
W S=1-\sum_{j=1}^{n}\left(2^{-R_{(I) j}} \frac{\left|R_{(I)_{j}}-R_{(I I)_{j}}\right|}{\max \left\{\left|1-R_{(I)_{j}}\right|,\left|n-R_{(I)_{j}}\right|\right\}}\right)
\end{gathered}
$$

where $R_{(I)_{j}} R_{(I I)_{j}}$ are ranks of the $k$ - criterion in the rankings being compared.

The approximation technique RS, RR or AC, will make it possible to determine the weights using the FCPR method that are closest to those obtained by using the same techniques for the full ranking voting method, and/or the averaged pairwise comparisons

matrix M. The obtained value $C$ will be as low as possible and the values of $r_{S}$ and $W S$ will be as close to 1 as possible.

\section{Area and Scope of Research}

The spatial preferences of students at the Faculty of Geodesy and Cartography of the Warsaw University of Technology regarding the location of residence during their studies, obtained through a simple geo-questionnaire, were analysed. The area under analysis included Warsaw, the capital city of Poland (Figure 3).

The Warsaw University of Technology (WUT) commenced its operations in 1895 as the Institute of Technology, and since 1915 as the Warsaw University of Technology-thanks to the efforts of the Association for Scientific Courses and the Citizens' Committee of the City of Warsaw. Today, over 180 student research groups, organisations and associations are active at the Warsaw University of Technology, and the educational offer includes more than 30 fields of study [82]. The Department of Geodesy and Cartography also has a long history and will celebrate its 100th anniversary in 2021. At present, the Faculty of Geodesy and Cartography teaches three courses: geodesy and cartography, spatial management and geoinformatics. The students are both residents of Warsaw and people coming to study from other parts of Poland. The WUT is located in the city centre. Residing in the vicinity guarantees the possibility of getting to labs quickly, though it comes with the inconvenience of living in the centre, mainly in the form of increased traffic and noise. Locations in the city outskirts generally provide better access to natural green spaces, but require an arduous commute to the centre and often do not provide as good access to cultural facilities such as theatres or cinemas, leisure activities (pubs, restaurants, and student clubs) or access to sports facilities. Access to the WUT is provided by public transport-a combination of bus, tram, metro and urban railways (Figure 4). 


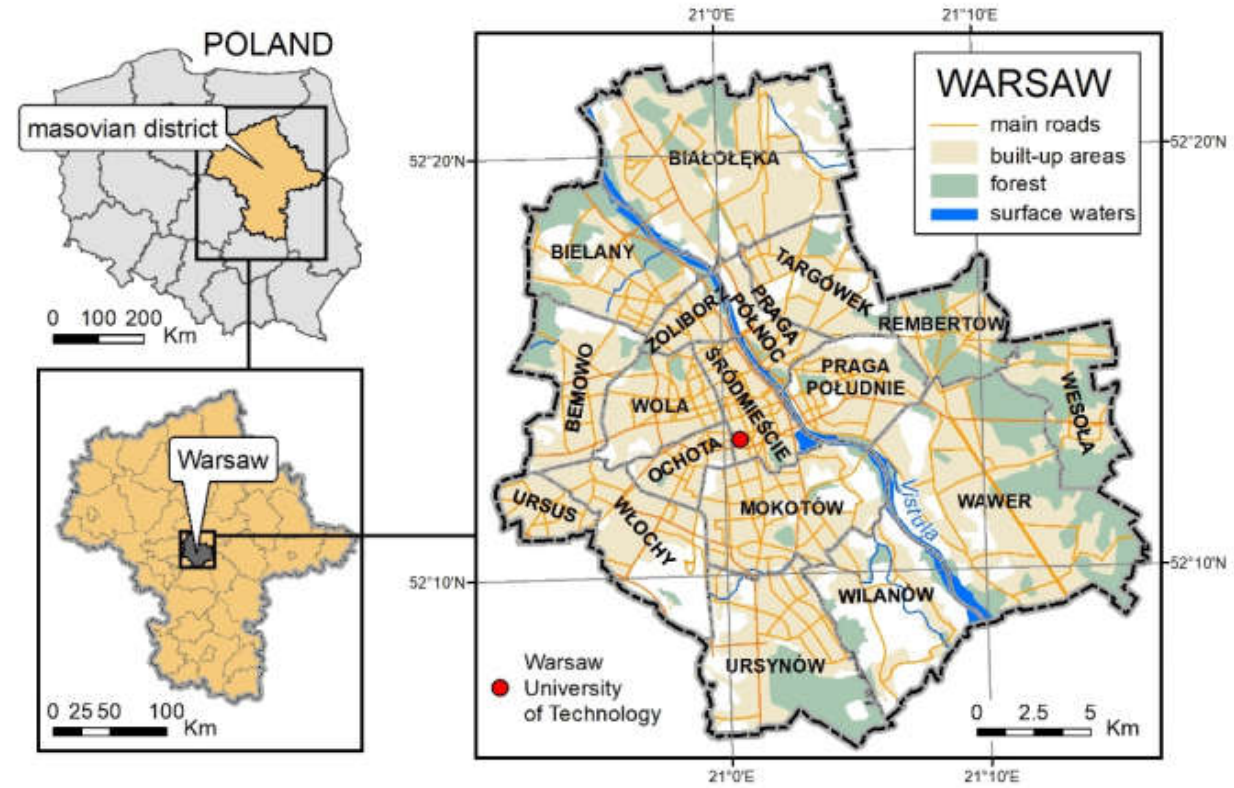

Figure 3. Warsaw: Area of research. Own study based on BDOT10k data-an integrated copy of the Database of Topographic Objects, with content and detail corresponding to a topographic map in the scale 1:10,000. Data made available free of charge through the download service from geoportal.gov.pl Available online: https:/ / mapy.geoportal.gov.pl/imap/Imgp_2.html (accessed on 21 April 2021) [81].

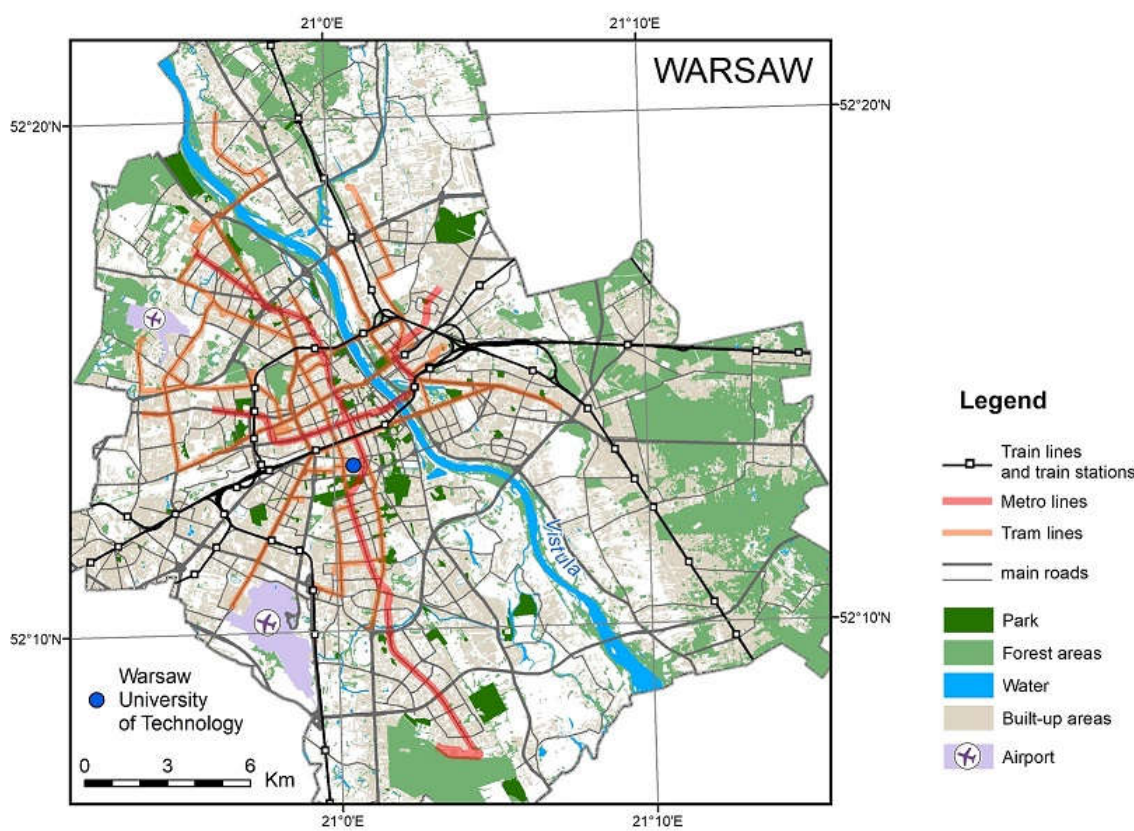

Figure 4. The main elements of public transport in Warsaw; own study based on data from BDOT10k.

Research Using a Simple Geo-Questionnaire

The simple geo-questionnaire was conducted over two periods: DATE(1) between 8 April 2019 and 30 May 2019, prior to the outbreak of COVID-19, when students were studying in the traditional full-time way. Responses were obtained from 121 participants; and DATE(2) between 12 November 2020 and 12 December 2020, during the second wave of the COVID-19 outbreak (Figure 5). During this period, students participated only in online classes. The DATE(2) survey received responses from 115 participants. In addition, a study involving an additional group of 50 students (the control group) was conducted during DATE(2). 


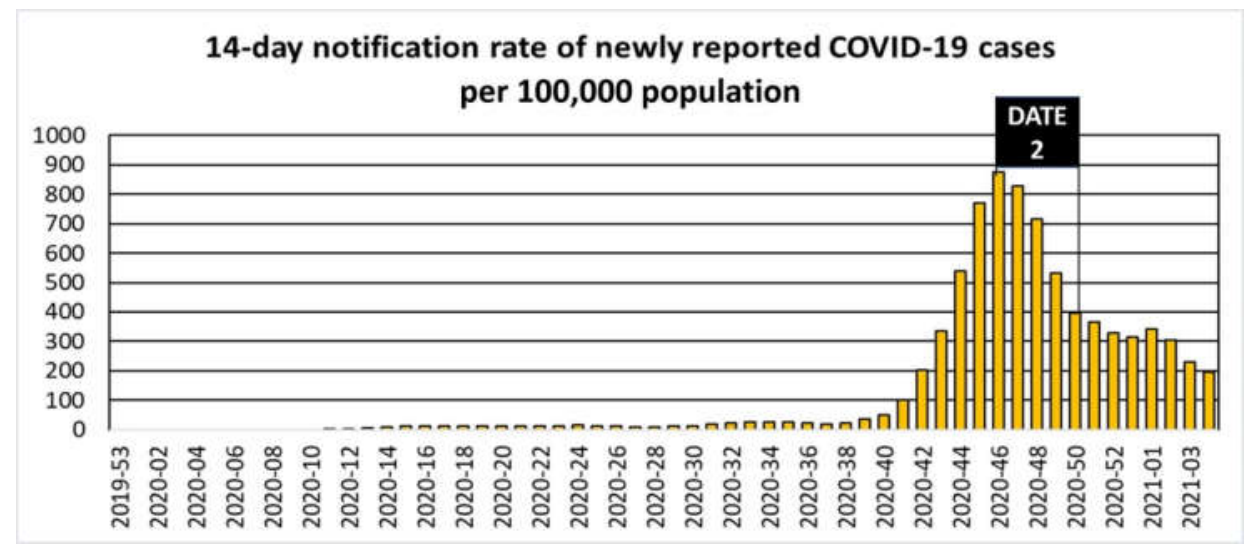

Figure 5. DATE(2) geo-questionnaire period against a graph showing the 14-day notification rate of newly reported COVID-19 cases per 100,000 population in Poland. The study was based on data from the European Centre for Disease Prevention and Control [83].

The research used a simple geo-questionnaire developed in earlier studies [84]. Each student completed a Google form which asked how long they had been living in Warsaw (not living, less than 2 years, 2-5 years or more than 5 years) and whether they planned to stay in the capital after graduation (yes, no or don't know). Next, each participant was introduced to the map service of Warsaw (mapa.um.warszawa.pl) and, on the basis of the information provided there and their own experience, indicated from 1 to 10 their most preferred locations. Coordinates of the points for the indicated locations (longitude $\mathrm{L}$ and latitude B in WGS8, EPSG: 4326) were entered into a Google form and saved, along with the answers to the questions. This allowed the responses to be spatially localised. Further on in the form, each student indicated the three most important criteria that guided them when giving their preferred locations. The criteria were divided into two groups and compiled in two lists (List No 1 and List No 2). The results for each list were analysed separately.

List No 1: K1: Nearby or good access to WUT (University); K2: Quiet, green and peaceful neighbourhood (Quiet); K3: Pubs, restaurants, or student clubs nearby (Pastimes); K4: Sports and recreation nearby: swimming pools, tennis courts, sports fields, etc. (Recreations); K5: Cinemas, theatres, culture facilities, nearby (Culture); K6: Schools, kindergartens, and playgrounds for children (Facilities for children).

List No 2: K1: Prestigious location; K2: Attractive neighbourhood/architecture; K3: Close to family, friends and job; K4: Modern housing estate; K5: Townhouses/old buildings; K6: Good investment.

\section{Results}

In the first phase, the study was conducted in the control group. The results allowed a suitable approximation weights technique to be determined for the developed FCPR method. The weighs were then determined from the geo-questionnaires and the results were analysed.

The control group consisted of 50 students who determined the full ranking of criteria set in List No 1, and also made pairwise comparisons of relative criteria significance in a matrix M. On the basis of the individual full rankings, partial rankings were determined in which the indications from the first three positions were taken into account $(k=3)$. Criteria weights were then determined using the RS, RR and AC approximation techniques on the full ranking, and using the FCPR method $(k=3)$ and the PCM (pairwise comparison matrix) method based on an averaged matrix of pairwise comparisons M. Seven sets of group weights of criteria were obtained.

The task of the control group was: firstly, to rank the criteria from List No 1; and secondly, to complete a matrix of pairwise comparisons. The task was made available to them on the learning platform, in the form of a prepared spreadsheet. The collected 
results from each student were checked for: (a) consistency of the assessments made in the pairwise comparisons matrix $\mathbf{M}(\mathrm{CR}<0.1)$; (b) compatibility of the declared ranking with the ranking of the criteria determined by the PCM method.

\subsection{Results Obtained in the Control Group}

In the set of 50 filled pairwise comparison matrices $\mathbf{M}$, nine contained inconsistent assessments of the criteria significance ( $C R>0.1)$, moreover, in seven cases, the resulting rankings of the criteria were different from the declared rankings. In addition, in eight pairwise comparison matrices, the criteria ranking determined from them were different from the declared one, even though they contained consistent pairwise comparisons. A total of 17 responses were problematic and so they were removed from the set of results. They represented $34 \%$ of all results. This shows that correctly assessing the significance of criteria using a pairwise comparison matrix ( $\mathrm{PCM}$ ) can be problematic. The remaining 33 responses were used to determine group weights using three methods:

1. The method of voting for the ranking (the RS, RR and AC techniques);

2. Using FCPR method $k=3$ (the RS, RR and AC techniques);

3. The averaged pairwise comparisons matrix method $\mathbf{M}$.

The counts of particular positions in the ranking for criteria were determined on the basis of 33 rankings adopted for the analysis and are presented in Table 1.

Table 1. Number of indications of particular criteria in subsequent positions in the ranking on the basis of the results obtained by respondents from the control group.

\begin{tabular}{ccccccccc}
\hline Criteria & $\mathbf{K j}$ & $N_{1}$ & $N_{2}$ & $N_{3}$ & $N_{4}$ & $N_{5}$ & $N_{6}$ & $N_{0}{ }^{1}$ \\
\hline university & $\mathrm{K} 1$ & 27 & 4 & 2 & 0 & 0 & 0 & 0 \\
quiet & $\mathrm{K} 2$ & 6 & 18 & 8 & 1 & 0 & 0 & 0 \\
pastime & $\mathrm{K} 3$ & 0 & 6 & 7 & 6 & 7 & 7 & 20 \\
recreation & $\mathrm{K} 4$ & 0 & 2 & 10 & 11 & 9 & 1 & 21 \\
culture & $\mathrm{K} 5$ & 0 & 1 & 4 & 12 & 12 & 4 & 28 \\
facilities for kids & $\mathrm{K} 6$ & 0 & 1 & 2 & 3 & 6 & 21 & 30 \\
\hline
\end{tabular}

${ }^{1} N_{0}=N_{4}+N_{5}+N_{6}$, is the number of criterion indications in rank position $r>3$.

Using Equations (14)-(17), the scores for the individual ranking positions were calculated $P_{r}$ and $P_{0}$ using approximation techniques RS, RR and AC; the results are summarised in Table 2.

Table 2. Points assigned to ranking positions, determined through the RS, RR and AC techniques.

\begin{tabular}{cccccccc}
\hline $\boldsymbol{r}$ & $\mathbf{1}$ & $\mathbf{2}$ & $\mathbf{3}$ & $\mathbf{4}$ & $\mathbf{5}$ & $\mathbf{6}$ & $\mathbf{4 , 5 , 6}$ \\
\hline $\boldsymbol{P}_{\boldsymbol{r}}$ & $\boldsymbol{P}_{1}$ & $\boldsymbol{P}_{2}$ & $\boldsymbol{P}_{3}$ & $\boldsymbol{P}_{4}$ & $\boldsymbol{P}_{5}$ & $\boldsymbol{P}_{6}$ & $\boldsymbol{P}_{0}$ \\
\hline $\mathrm{RS}$ & 6.000 & 5.000 & 4.000 & 3.000 & 2.000 & 1.000 & 2.000 \\
$\mathrm{RR}$ & 1.000 & 0.500 & 0.333 & 0.250 & 0.200 & 0.167 & 0.203 \\
$\mathrm{AC}$ & 2.000 & 1.333 & 1.000 & 0.750 & 0.533 & 0.333 & 0.536 \\
\hline
\end{tabular}

After calculating the scores, the weightings of the criteria were determined using the $\mathrm{RS}, \mathrm{RR}$ and AC techniques on the basis of the full ranking $w_{j}(I)$ and using the FCPR method $w_{j}(I I)$ and the $C$-values of the squared distance norm, denoted as: $C_{I-I I}$, was calculated. Using 33 pairwise comparison matrices $\mathbf{M}$ completed by students in the control group, an average matrix was calculated $\mathbf{M}$, and a set of weights for the criteria was determined: $w_{j}(\overrightarrow{\mathbf{M}})$. The matrix consistency index $\overline{\mathbf{M}}$ amounted to $C R=0.004$. This set of weights was compared with the previously determined sets by calculating the values of $C$, marked as: $C_{\mathbf{M}}$. The results are summarised in Table 3 . 
Table 3. The values $C$ calculated for the sets of weighs determined by the RS, RR and AC techniques in the ranking voting method $w_{j}(I)$ and FCPR method $w_{j}(I I)$ and determined from the averaged pairwise comparisons matrix $w_{j}(\overline{\mathbf{M}})$.

\begin{tabular}{|c|c|c|c|c|c|c|c|c|}
\hline \multirow[b]{2}{*}{ Criteria } & \multirow[b]{2}{*}{$\mathbf{K j}$} & \multicolumn{2}{|c|}{ RS } & \multicolumn{2}{|c|}{ RR } & \multicolumn{2}{|c|}{ AC } & \multirow{2}{*}{$\begin{array}{r}\text { PCM }^{1} \\
- \\
w_{j}(\bar{M})\end{array}$} \\
\hline & & $w_{j}(I)$ & $w_{j}(I I)$ & $w_{j}(I)$ & $w_{j}(I I)$ & $w_{j}(I)$ & $w_{j}(I I)$ & \\
\hline \multirow{8}{*}{$\begin{array}{l}\text { university } \\
\text { quiet } \\
\text { pastime } \\
\text { recreation } \\
\text { culture } \\
\text { facilities } \\
\text { for kids }\end{array}$} & K1 & 0.275 & 0.276 & 0.368 & 0.371 & 0.314 & 0.315 & 0.387 \\
\hline & K2 & 0.233 & 0.230 & 0.222 & 0.221 & 0.229 & 0.226 & 0.249 \\
\hline & K3 & 0.141 & 0.142 & 0.117 & 0.117 & 0.131 & 0.132 & 0.105 \\
\hline & K4 & 0.148 & 0.134 & 0.112 & 0.107 & 0.133 & 0.123 & 0.114 \\
\hline & K5 & 0.123 & 0.112 & 0.098 & 0.094 & 0.113 & 0.104 & 0.088 \\
\hline & K6 & 0.080 & 0.106 & 0.082 & 0.091 & 0.081 & 0.100 & 0.056 \\
\hline & $C_{I-I I}$ & \multicolumn{2}{|c|}{$C_{I-I I}^{R S}=0.0323$} & \multicolumn{2}{|c|}{$C_{I-I I}^{R R}=0.0111$} & \multicolumn{2}{|c|}{$C_{I-I I}^{A C}=0.0235$} & \\
\hline & $C_{\mathbf{M}}=$ & 0.1296 & 0.1319 & 0.0441 & 0.0496 & 0.0892 & 0.0929 & \\
\hline
\end{tabular}

${ }^{1}$ PCM-pairwise comparison method.

Based on the determined sets of weights, the criteria were ranked and the similarity of the rankings was determined by rank correlation coefficients: $r_{S}(20)$ and $W S$ (21). The results are summarised in Table 4.

Table 4. Rankings of the criteria based on the set of weights.

\begin{tabular}{|c|c|c|c|c|c|c|c|c|}
\hline \multirow[b]{2}{*}{ Criteria } & \multirow[b]{2}{*}{$\mathbf{K j}$} & \multicolumn{2}{|c|}{ RS } & \multicolumn{2}{|c|}{ RR } & \multicolumn{2}{|c|}{ AC } & \multirow{2}{*}{$\begin{array}{c}\text { PCM } \\
- \\
(\mathbf{M})\end{array}$} \\
\hline & & (I) & (II) & (I) & (II) & (I) & (II) & \\
\hline university & $\mathrm{K} 1$ & 1 & 1 & 1 & 1 & 1 & 1 & 1 \\
\hline quiet & $\mathrm{K} 2$ & 2 & 2 & 2 & 2 & 2 & 2 & 2 \\
\hline pastime & K3 & 4 & 3 & 3 & 3 & 4 & 3 & 4 \\
\hline recreation & $\mathrm{K} 4$ & 3 & 4 & 4 & 4 & 3 & 4 & 3 \\
\hline culture & K5 & 5 & 5 & 5 & 5 & 5 & 5 & 5 \\
\hline $\begin{array}{l}\text { facilities } \\
\text { for kids }\end{array}$ & K6 & 6 & 6 & 6 & 6 & 6 & 6 & 6 \\
\hline
\end{tabular}

The resulting criterion rankings are compatible, or there is a change in position between $r=3$ and $r=4$. For compatible rankings $r_{S}=1$ and $W S=1$, for a change in position 4 and 3 in the rankings, the coefficient values are $r_{S}=0.9429$ and $W S=0.9375$, respectively. Referring to the suggested linguistic terms (using trapezoidal fuzzy numbers) proposed by Sałabun and Urbaniak [80] for WS $>0.808$, the ranking similarity is high. The observed results can be summarised as follows:

- The differences in weights obtained using the RS, RR and AC techniques after changing from the full ranking of criteria to the FCPR method, in which respondents indicated the first three criteria only, were smaller than the differences in weights when the PCM method based on the averaged matrix of pairwise comparisons $\mathbf{M}$ was used;

- The smallest differences in the values of weights were obtained for the RR technique;

- The similarity of the resulting rankings assessed by the coefficient WS is high.

The studies conducted in the control group allowed the criteria weight approximation technique to be selected, which was then used in the developed FCPR method to determine the group weights of criteria based on the results obtained from geo-questionnaires carried out over the periods DATE(1) and DATE(2) - which involved the same number of criteria and values of $k$. As it demonstrated the smallest differences in the values of the weights, the RR approximation technique was adopted. The analysis carried out also allowed us to conclude that the criteria weights obtained by the FCPR method are reliable, while at the same time the process of ranking the criteria had been as simplified as far as possible. 


\subsection{Results Obtained in the Research Using the Geo-Questionnaire}

In a simple geo-questionnaire conducted over two periods: DATE(1) and DATE(2), from the two lists of criteria (List No 1 and List No 2) students indicated their three most important criteria for selecting preferred locations. The FCPR (RR) method was then applied and the criteria weights were determined. The results for List No 1 are summarised in Table 5 and the results for List No 2 in Table 6. For greater readability, the values of the weights are shown as percentages.

Table 5. Resulting weights of the criteria in List No 1.

\begin{tabular}{ccccccc}
\hline List No1 & \multicolumn{4}{c}{ Weights (\%) } & \multicolumn{2}{c}{ Rankings } \\
\hline Criteria & Kj & DATE(1) & DATE(2) & $\boldsymbol{\Delta ( I - I I )}$ & DATE(1) & DATE(2) \\
\hline university & K1 & 34.5 & 33.3 & -1.2 & 1 & 1 \\
quiet & K2 & 20.4 & 20.5 & 0.1 & 2 & 2 \\
pastime & K3 & 11.7 & 11.9 & 0.2 & 5 & 5 \\
recreation & K4 & 12.3 & 12.0 & -0.3 & 3 & 4 \\
culture & K5 & 11.8 & 12.8 & 1.0 & 4 & 3 \\
facilities for kids & K6 & 9.3 & 9.5 & 0.2 & 6 & 6 \\
\hline$r_{S}=0.9429, W S=0.9375:$ high similarity of criteria ranking. $C=1.6186$. &
\end{tabular}

Table 6. The resulting weights of the criteria from List No 2.

\begin{tabular}{ccccccc}
\hline List No2 & \multicolumn{3}{c}{ Weights (\%) } & \multicolumn{2}{c}{ Rankings } \\
\hline Criteria & Kj & DATE(1) & DATE(2) & $\boldsymbol{\Delta ( I - I I )}$ & DATE(1) & DATE(2) \\
\hline prestigious location & K1 & 12.4 & 11.6 & -0.8 & 5 & 6 \\
neighborhood/ architecture & K2 & 24.0 & 21.1 & -2.9 & 1 & 2 \\
close to my family, friends, my job & K3 & 21.0 & 23.5 & 2.5 & 2 & 1 \\
modern housing estate & K4 & 15.0 & 14.0 & -1.0 & 4 & 4 \\
townhouses/old building & K5 & 10.8 & 12.0 & 1.2 & 6 & 5 \\
good investment & K6 & 16.8 & 17.8 & 1.0 & 3 & 3 \\
\hline
\end{tabular}

$r_{S}=0.8857, W S=0.8266$ : high similarity of criteria ranking; $C=4.3290$.

For the criteria in List No 1, the weights of the criteria are similar, the largest difference being the $1.2 \%$ decrease in the importance of the criterion of good access to the WUT (K1: University), but even after the outbreak of the pandemic, it was still rated by students as by far the most important criterion for choosing a place to live. The highest increase of $1.0 \%$ was achieved by the <Cinemas, theatres, culture facilities, nearby $>$ (K5: Culture) criterion. In second place in the ranking is the $<$ Quiet, green and peaceful neighbourhood $>$ (K2: Quiet) criterion. Both in the survey before and after outbreak of the COVID-19 pandemic, the resulting values of weights for this criterion are almost identical $(20.4 \%$; $20.5 \%)$. Comparing the values of the criteria weights from List No 1 between DATE(1) and DATE(2) gave: $\mathrm{C}=1.6186$. The differences in the values of the weights are greater than when changing the method of determining them in the control group. The criteria rankings changed between positions 3 and 4, exactly the same as when the method of determining the weights was changed in the control group. The index WS $=0.9375$ indicates the high similarity of the rankings obtained.

For the List No 2 criteria, there was less similarity in terms of weights between the results obtained from the DATE(1) and DATE(2) geo-questionnaires. The largest decrease in criterion importance was recorded for K2: $<$ Neighbourhood/architecture $>(-2.9)$ and the largest increase in criterion importance was for K3: <Close to my family, friends, my job $>(+2.5)$. At the same time, there was a change in the first place in the ranking. It was the criterion of choosing a location close to family, friends and work that topped the ranking in the DATE(2) geo-questionnaire during the pandemic. The change in the weights of the List No 2 criteria is also illustrated by the higher value of $C=4.3290$. The lower value of the rank similarity coefficient WS $=0.8266$ indicates less similarity of the criteria rankings, although the similarity can still be considered high. 
As regards answers to the question "Do you want to live in Warsaw after graduation?" in the geo-questionnaire conducted on DATE(1), the answer "yes" was given by $52.1 \%$, "don't know" by $28.1 \%$ and "no" by $19.8 \%$ of respondents. By contrast, in the geo-questionnaire on DATE(2), these three answers were given by $48.8 \%, 30.6 \%$ and $20.7 \%$ respectively. There is a slight decrease in the number of affirmative answers in favour of "don't know", while the percentage of those who declared no desire to live in Warsaw after graduation remained at a similar level. In the geo-questionnaire, students declared how long they had already lived in the city (more than 5 years, 2-5 years, less than 2 years and "I don't live in Warsaw"). Responses to the question on the desire to live in Warsaw after graduation were analysed by group of students, determined according to the duration of residence in the city (Figure 6). An interesting observation is the increase in uncertainty and a decrease in declared desire to live in Warsaw after graduation in the group of people living in the city for more than 5 years, i.e., those with the greatest family, social and often professional ties to the city.

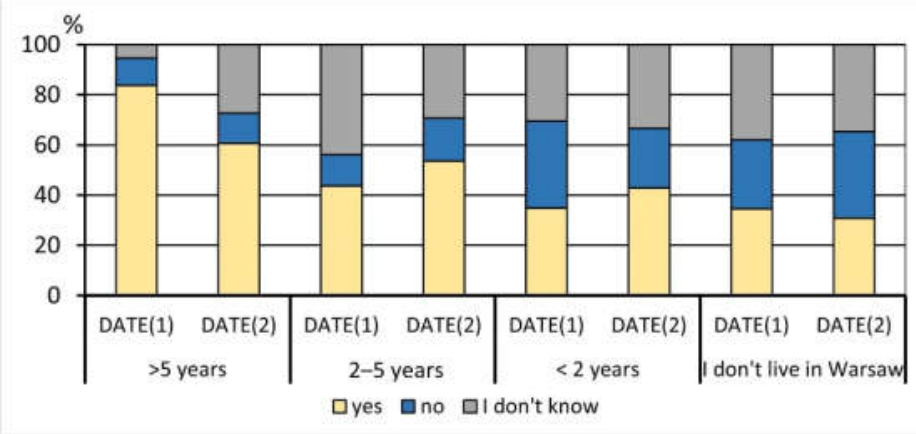

Figure 6. Percentage share of answers "yes", "no", "don't know" to the question: do you want to live in Warsaw after graduation in geo-questionnaires from DATE(1) and DATE(2), broken down into groups of students depending on how long they have lived in Warsaw.

We also compared the obtained criteria weights in the DATE(1) and DATE(2) geoquestionnaires, broken down by groups of students on the basis of their answers to the question concerning the time of their residence in Warsaw (Figure 7).

List No 1-for all groups of students, two criteria are most important: good access to the university (K1) and a quiet and peaceful neighbourhood (K2). Comparing the results from both periods, it can be observed that, in the groups of students who have lived in Warsaw for a shorter period of time, the criterion of commuting to WUT slightly decreases in importance, while, in the group of students who have lived there more than five years, the importance of this criterion has slightly increased. In all the groups, the criterion of a quiet and peaceful neighbourhood remained at a similar level or slightly increased in significance.

List No 2-for groups of students excluding those who did not live in Warsaw during their studies, a clear change is visible: the criterion "neighbourhood/architecture" loses its importance in favour of "close to my family, friends, my job" as the leading one. This change is particularly noticeable for the group of students who have lived in Warsaw for more than 5 years. These are generally people with strong family ties and often already professional ties to the city. They have close family living in the city, as well as friends not only from their studies, but also from earlier stages of education. The reassessment of the "good investment" criterion also seems interesting. With the exception of the group of students who have lived in Warsaw for less than two years, the importance rating of this criterion increased compared to others, and this is particularly evident in the group of students not living in Warsaw. For them, choosing a flat located in the capital, should they buy it during their studies, would most importantly be a good investment of their capital for the future. 


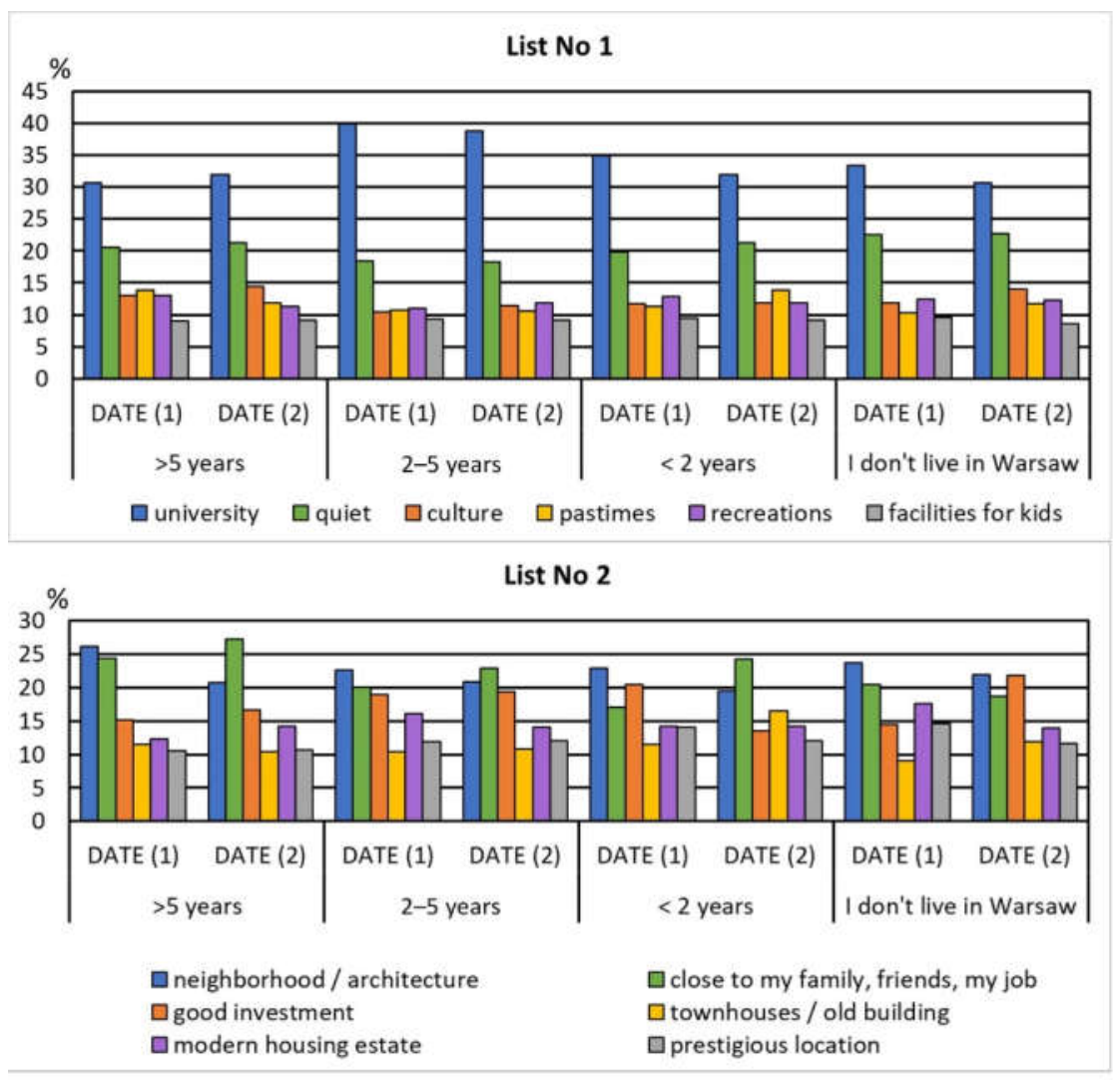

Figure 7. The values of the criteria weights in List No 1 and List No 2 determined from the DATE(1) and DATE(2) geo-guestionnaires, based on results in groups of students broken down by the time they lived in the city.

We determined the values of $C, r_{S}$ and $W S$ between DATE(1) and DATE(2) sets of criteria weights and rankings based on the results in groups of students, broken down by the time they have lived in the city (Table 7).

Table 7. Calculated values: $C, r_{S}$ and $W S$ showing the similarity between the group weights of criteria obtained for results DATE(1) and DATE(2) in groups of students, broken down by the time they have lived in the city.

\begin{tabular}{cccccc}
\hline & List & >5 Years & 2-5 Years & $<2$ Years & Don't Live in Warsaw \\
\hline C & No 1 & 3.281 & 1.766 & 4.318 & 3.923 \\
& No 2 & 6.632 & 4.011 & 11.728 & 9.546 \\
\hline \multirow{2}{*}{$r_{S}$} & No 1 & 0.943 & 0.943 & 0.829 & 0.943 \\
& No 2 & 0.886 & 0.943 & 0.314 & 0.543 \\
\hline \multirow{2}{*}{$W S^{1}$} & No 1 & 0.948 & 0.979 & 0.938 & 0.958 \\
& No 2 & 0.778 & 0.792 & 0.607 & 0.847 \\
\hline
\end{tabular}

${ }^{1}$ linguistic terms of ranking similarity coefficient WS are: Low $(W S<0.234)$, Medium $(0.352<W S<0.689)$ and High (WS > 0.808) [80].

The results collected in Table 7 show that the group weights of the criteria from list No 2 show less similarity. The lowest similarity exists between the results of the groups of students who indicated over periods DATE(1) and DATE(2) that they have lived in the city for less than two years.

Indicated Preferred Housing Locations

Students indicated their preferred locations; these are shown in Figure 8. 


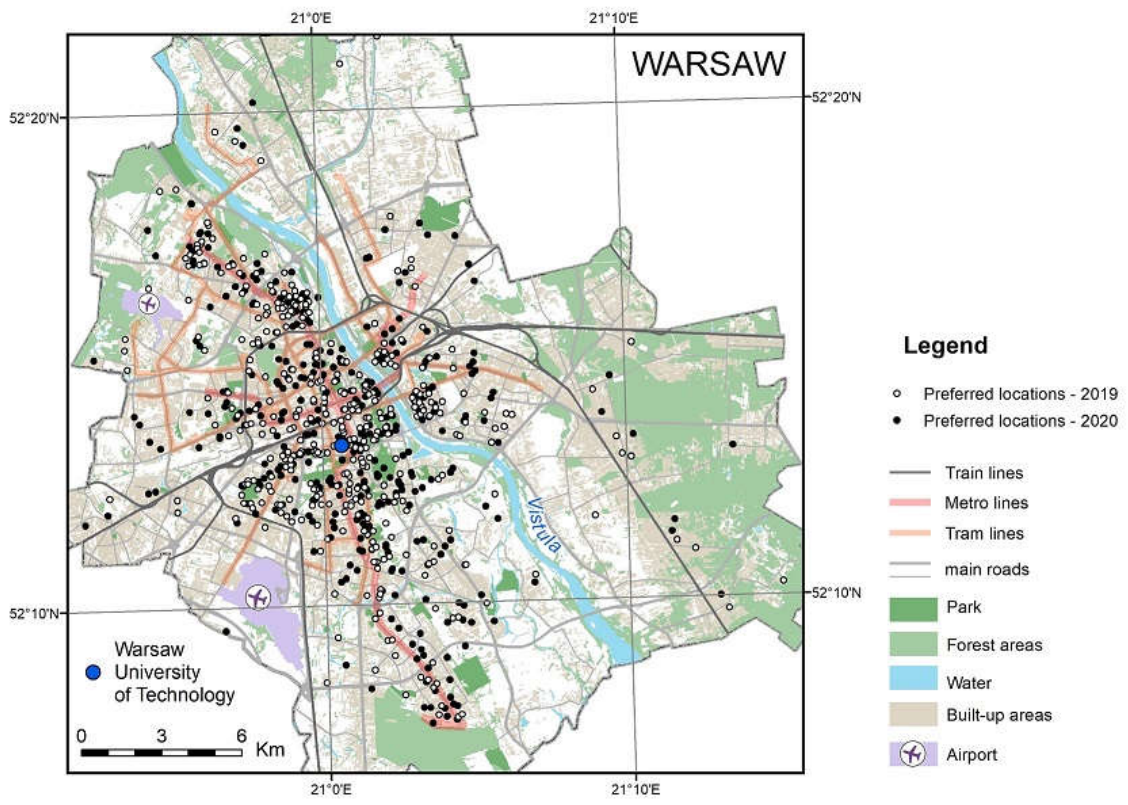

Figure 8. Locations indicated by students in geo-questionnaires DATE(1) and DATE(2), background map-own compilation of BDOT10k data.

After conducting the DATE(1) and DATE(2) geo-questionnaires, the travel times by public transport, bicycle and car from the locations indicated by the students to the WUT were read out from Google Maps, assuming average weekday traffic congestion, with the arrival time to the WUT set at 8:30 am. In addition, access times were read out at generated points arranged in a regular $500 \mathrm{~m} \times 500 \mathrm{~m}$ grid. Figure 9 shows the results of interpolating (Kernel Density ArcMap ESRI) the travel times to the WUT.

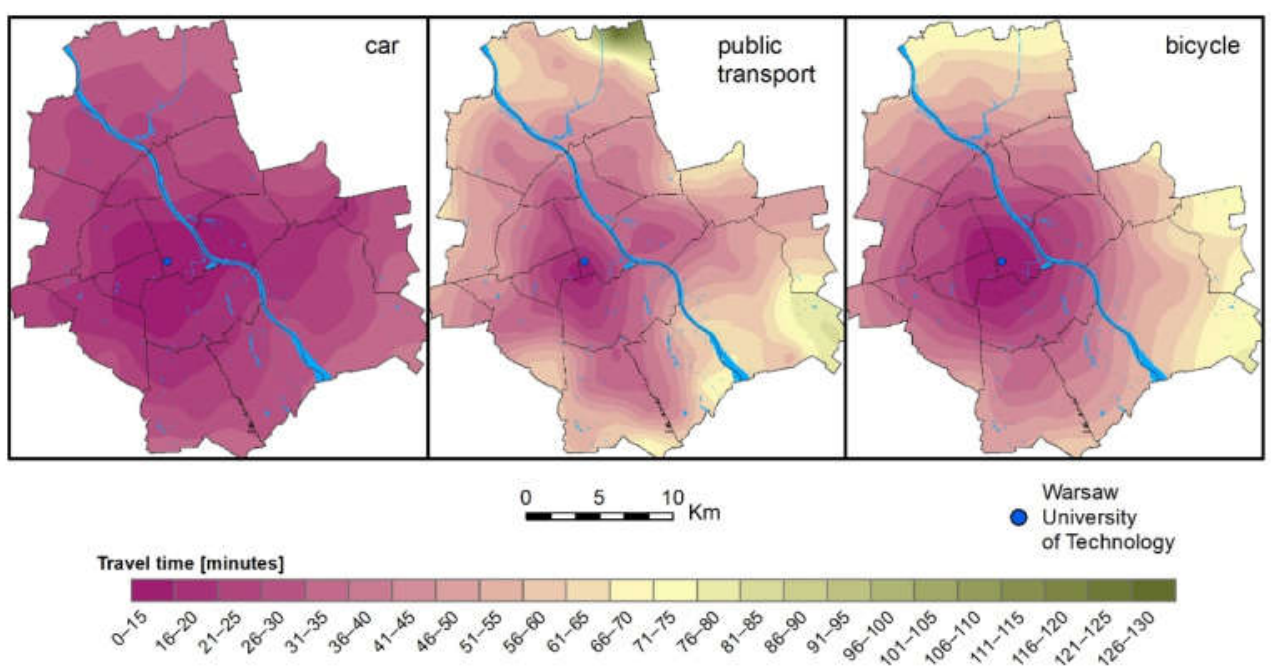

Figure 9. Travel times to the WUT by car, public transport and bicycle, interpolated from readings of Google Maps.

A large convergence of results is visible after plotting on the map the travel time by public transport from the locations indicated by students who gave $\mathrm{K} 1<$ nearby or good access to WUT> as the most important criterion in the survey (Figure 10). The convenience of getting to the WUT by public transport seems to be the most important. 


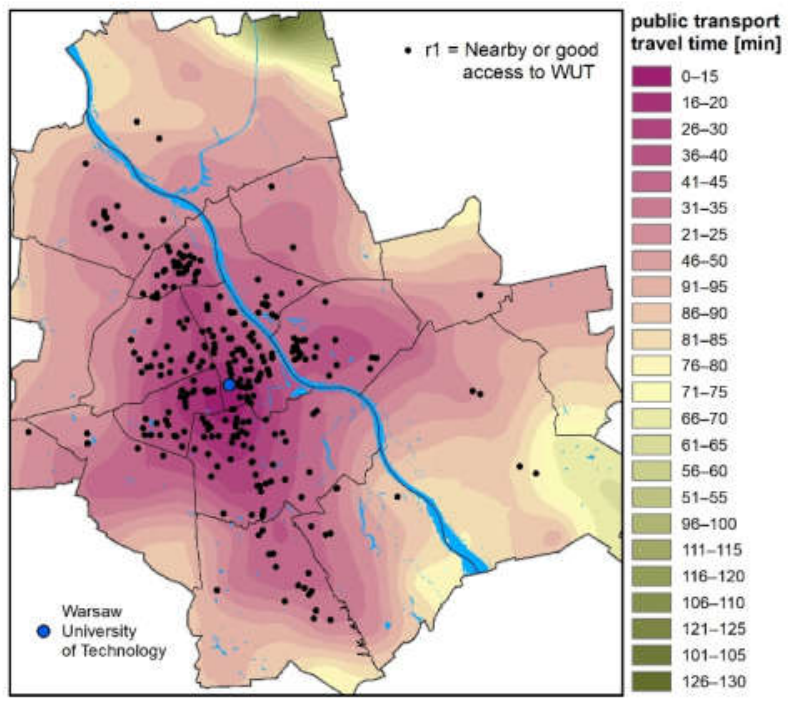

Figure 10. Locations indicated by students who chose $\mathrm{K} 1<$ nearby or good access to the WUT $>$ in first place in the geo-questionnaire, in comparison with the time of commuting to WUT by public transport.

The percentage of indicated locations (K1) from which it is possible to reach the WUT by public transport in time was determined at: 20,30, 40, 50 and $60 \mathrm{~min}$. Figure 11 shows a graph based on the obtained DATE(1) and DATE(2) results. It can be seen that the students indicated fewer locations (K1) <near the WUT> in the DATE(2) period than in the DATE(1) period.. This is also confirmed by the decrease in significance of this criterion compared to other criteria between DATE(1) and DATE(2).

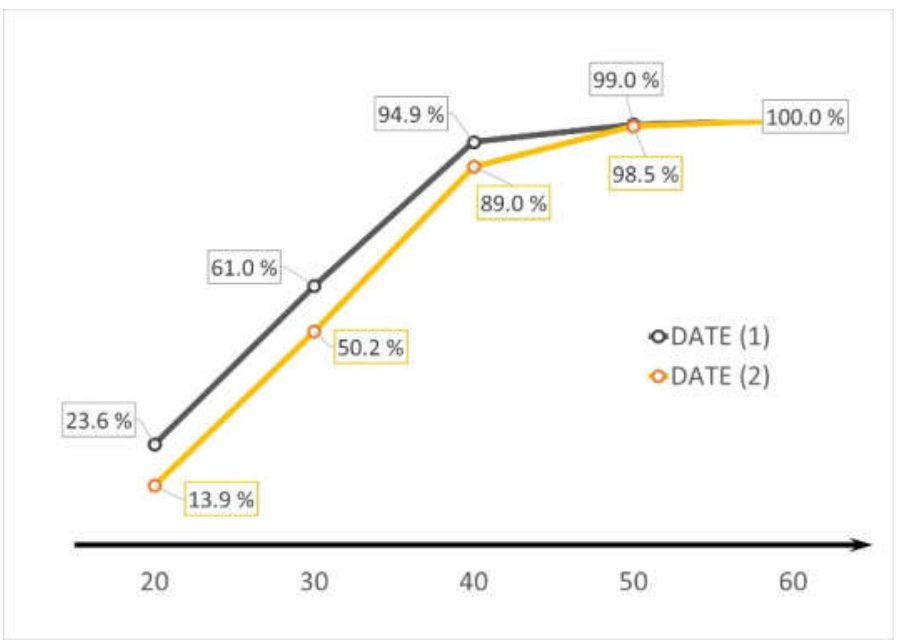

Figure 11. Percentage of indicated locations in commuting time: $20,30, \ldots, 60 \mathrm{~min}$ to the WUT.

Some locations for which K1: nearby or good access to WUT, was declared as the most important criterion were indicated in areas with poor connections to the city centre, from which access to the WUT by public transport takes more than $45 \mathrm{~min}$. A similar situation also exists in the research conducted during DATE(2). This type of observation can be considered an outlier. Boundary commuting times were set by taking the value corresponding to the following as an upper limit to the commuting time: Q3 + 1.5 IQR, where IQR is the inter-quartile range (The difference between the values that correspond to the third and the first quartile), and Q3 is the value that corresponds to the third quartile. Table 8 summarises the basic descriptive statistics for the set of commuting times from the indicated locations (K1: nearby or good access to the WUT). 
Table 8. Descriptive statistics of travel times (minutes) by public transport for locations indicated by students who ranked K1: nearby or good access to the WUT in first place.

\begin{tabular}{ccc}
\hline Statistic & DATE(1) & DATE(2) \\
\hline min & 13.2 & 12.3 \\
max & 67.1 & 63.6 \\
Q3 & 32.0 & 35.0 \\
Q1 & 21.1 & 24.7 \\
IQR & 10.9 & 10.3 \\
median & 27.7 & 30.0 \\
mean & 27.4 & 30.2 \\
SD & 8.7 & 9.1 \\
Q3 + 1.5 IQR & 48.4 & 50.5 \\
MEAN + SD & 36.1 & 39.2 \\
\hline
\end{tabular}

Outlier observations. Despite the selection of criterion K1 as the first ranking criterion, students who indicated outlier locations were apparently not guided by this criterion. Outlier observations on both DATE(1) and DATE(2) were results of the geo-questionnaire in which students declared they had no desire to live in Warsaw after graduation, and/or indicated the criterion of location close to their family, friends or work as the most important criterion from List No 2.

Although the majority of students indicated criterion K1: <nearby or good access to the WUT> as the most important criterion compared to other criteria in List No 1, based on Figure 10 and Table 8, it can be seen that, when indicating preferred locations, students have different understandings of this criterion, they have different tolerances for it, or are guided largely by other considerations not revealed by the set of criteria in List No 1. Often, these are individual considerations, difficult to capture using spatial maps for the value of the criteria for the whole group of students-such as proximity of residence to family, friends or place of work.

Carrying out a multi-criteria analysis in which both the stated criteria weightings are determined and the preferred locations (revealed preferences) are indicated allows for more complete information on housing preferences.

\section{Discussion}

In cities that are important academic centres, the population surge is also linked to university graduates who decide to stay in the city after graduation. Young people are looking for places to live that are, above all, well connected to the city centre and offer the comfort of living in peace and quiet. The level of importance of the criterion of choosing a quiet and peaceful place to live did not change between the study periods. Quiet and peaceful places, especially natural green areas, can relieve stress [85], and mechanical noise adversely affects the well-being of students during lockdown [86]. The preference for the residence location was mainly due to evaluating the level of comfort (convenient commuting, peace and quiet), with the relative importance of these criteria reaching $34.5 \%$ and $20.4 \%$ respectively for DATE(1), and $33.3 \%$ and $20.5 \%$ for DATE(2). The other four criteria analysed in List No 1 had relative significances of about $10 \%$, so the significances are respectively three and two times lower. These other criteria described the possibility of visiting restaurants, pubs, student clubs, sports and recreation, culture, as well as places providing attractive leisure activities and facilities for children.

For the List No 2 of criteria, comparing the results obtained from the DATE(1) and DATE(2) geo-questionnaires revealed that the largest decrease was in criterion K2: <Neighbourhood/architecture > importance (-2.9), and the largest increase was in criterion K3: $<$ Close to my family, friends, my job $>$ importance $(+2.5)$. At the same time, there was a change in the first place in the ranking. If a change of criterion weight leads to a change in the ranking of the criteria, then, in GIS-MCDA, it is considered a significant weight change (rank reversals, e.g., [87-89]). For the criteria set in the list No 2, a change of 
weights caused a criterion replacement at the first place of the ranking, which is a very significant change. Moreover, the determined rank coefficients showed less similarity of the group weights than in the case of changing the method or technique of determining the weight in the control group. The results obtained for List No 2 criteria indicated that it was important for students to maintain social ties, appreciated in particular during the pandemic period: ensuring close proximity to family or friends, a short distance from the workplace, without having to travel longer distances. The increased importance during the pandemic of a criterion that takes into account the distance to the place of residence of family and friends is confirmed, among other things, by the results of a study conducted in Japan by Uehar et al. [90], in which it was shown that the relationship with people is the most important factor influencing the assessment of stress levels during the pandemic, surpassing the living environment (big cities, rural areas), the type of housing, and the decrease in income.

The locations identified, both before and during the pandemic, showed a significant relationship between the attractiveness of the place of residence and access to efficient public transport. This confirms the role of transport in sustainable urban development, as emphasised in numerous studies, e.g., [91]. In the conducted research, students declared criterion K1: good access or close to the WUT as being very important. The university is one of the main central places [92] playing an important role in students' lives. Despite these declarations, the chosen locations varied in terms of travel time to the WUT. At the same time, the relationship with the availability of convenient public transport was evident (Figure 10). Despite the fact that classes only took place online during the pandemic, and students did not have to commute to universities for lectures, the significance rating of this criterion slightly decreased. By contrast, approximately $10 \%$ fewer locations in DATE(2) were identified from which it takes less than $30 \mathrm{~min}$ to commute to the WUT. There was little evidence of a "centrifugal tendency" to choose locations further from the centre.

The executed research did not take into account the economic aspect, which in reality can have a significant influence on the choice of location of a future house. At a later stage of the research, the results obtained will be compared with data on the real estate market and the age structure of the current buyers of flats. Assessing housing prices in various neighbourhoods against the average earnings of university of technology graduates would allow zones of economic accessibility of the location to be determined.

The evaluation of the FCPR method carried out was based on the empirical results in the control group. Respondents declared a ranking of the first three criteria and the full list of criteria was six items. Further analysis is needed, in particular with different variants of the number of $k$ against $n$ (the number of criteria). This will also be the subject of further research.

The compatibility of the stated preferences with the indicated locations was only indirectly assessed. The locations indicated by students who declared criterion K1: "nearby or good access to the WUT" as the most important were compared against a map of the time it takes to get to the WUT by public transport. The methodology and the analysis carried out in fuller detail will be the subject of further research.

In our research, we wanted to develop and test a simplified method for determining group weights of criteria. However, we also were curious whether the pandemic would have an influence on the results, if we repeated our research during the pandemic. For this purpose, we used the results obtained in 2019 from a very simple geo-questionnaire, and repeated the process with an identical form in 2020. In our research, we did not use use a statistically validated survey.

\section{Conclusions}

Despite a slight decrease, a majority of students who took part in the geo-questionnaire said they wanted to stay in the city after graduation. An analysis of their housing preferences indicated the continued importance of convenient commuting to the university, despite the persistence of distance (online) learning. A simultaneous analysis of the group 
weights determined on the basis of the ranking of criteria using the FCPR method (stated preferences SP) and revealed locations (revealed preferences RP), showed that not only commuting time, but also access to convenient public transport, is important. The criterion of location in a quiet, peaceful and green area was maintained at a consistently high level. At the same time, comparing the results before and during the pandemic showed a significant increase in the importance of being located close to family, friends and the workplace. Similar findings can be observed in studies conducted in other regions of the world (for example [90]). Translated into liveable city planning issues, it seems that the idea of neighbourhood units will grow in strength. Confronting the results of the survey carried out in a group of young people who will soon be looking for their own place with the analysis of "urban voids" (post-industrial, post-railway areas) may activate the creation of new residential buildings offering affordable housing, e.g., within an institutional rental system.

The developed FCPR voting methodology for the $k$ first ranking positions makes it extremely simple to obtain stated preferences for a large group of respondents. Complicated forms for the paired comparison method (PCM), or the need to indicate the full ranking of criteria, may discourage respondents from taking part in the research. It has been shown that the results obtained by the simplified method bring similar results to other methods for determining the group weights of criteria importance: determined by voting for the full ranking of criteria, or based on an averaged matrix of pairwise comparisons. The obtained results of the group weights of the criteria significance, and their change over time, can be used to assess changes in housing preferences of the whole group. However, it gives the full picture only when supplemented with the indicated preferred locations.

Author Contributions: Conceptualisation, J.J.; methodology, J.J.; software, J.J; validation, J.J. and A.M.; formal analysis, J.J. and A.M.; investigation, J.J.; resources, J.J.; data curation, J.J.; writingoriginal draft preparation, J.J.; writing—review and editing, A.M.; visualisation, J.J.; supervision, J.J.; project administration, J.J.; funding acquisition, J.J. All authors have read and agreed to the published version of the manuscript.

Funding: This research was funded by Warsaw University of Technology within the Research Grants Programme: “Grant naukowy w roku 2020 dla pracowników Politechniki Warszawskiej wspierajacego prowadzenie działalności naukowej w Dyscyplinie Inżynieria Lądowa i Transport" ("scientific grant in 2020 for employees of the Warsaw University of Technology supporting the conduct of scientific activity in the Discipline of Civil Engineering and Transport" (agreement of 2 July 2020)", Grant No. 504/04513/1060/43.070005.

Acknowledgments: The authors appreciate the assistance of students of the Faculty of Geodesy and Cartography who took part in the geo-questionnaires and the research carried out in the control group for their time and commitment.

Conflicts of Interest: The authors declare no conflict of interest.

\section{References}

1. Lynch, K. A Theory of Good City Form; MIT Press: Cambridge, MA, USA, 1981.

2. Jacobs, A.; Appleyard, D. Toward an Urban Design Manifesto. Null 1987, 53, 112-120. [CrossRef]

3. Lovins, L.H.; Cohen, B. Climate Capitalism: Capitalism in the Age of Climate Change, 1st ed.; Hill and Wang: New York, NY, USA, 2011; ISBN 978-0-8090-3473-4.

4. Kourtit, K.; Nijkamp, P.; Wahlström, M.H. How to Make Cities the Home of People-A 'Soul and Body' Analysis of Urban Attractiveness. Land Use Policy 2020, 104734. [CrossRef]

5. Carmona, M.; Heath, T.; Oc, T.; Tiesdell, S. Public Places Urban Spaces, Second Edition: The Dimensions of Urban Design, 2nd ed.; Architectural Press: Amsterdam, The Netherlands, 2010; ISBN 978-1-85617-827-3.

6. Delevoy, R.L.; Vidler, A.; Krier, L. Rational Architecture: The Reconstruction of the European City / Architecture Rationnelle: La Reconstruction de La Ville Europeenne; AAM Editions: New York, NY, USA, 1993; ISBN 978-2-87143-007-0.

7. Charlot-Valdieu, C.; Outrequin, P. L'urbanisme Durable: Concevoir un écoquartier; MONITEUR: Paris, France, 2011; ISBN 978-2-28119501-9.

8. Assen, S.V.; Boomen, T.V.D.; Broekman, M.; Eyck, G.V. Urban Challenges, Resilient Solutions: Design Thinking for the Future of Urban Regions; Valiz/Trancity: Haarlem, The Netherlands, 2017; ISBN 978-94-92095-33-6.

9. Banai, R. Pandemic and the Planning of Resilient Cities and Regions. Cities 2020, 106, 102929. [CrossRef] [PubMed] 
10. Jabareen, Y.; Eizenberg, E. The Failure of Urban Forms under the COVID-19 Epidemic: Towards a More Just Urbanism. Town Plan. Rev. 2021, 92, 57-63. [CrossRef]

11. Fabris, L.M.F.; Camerin, F.; Semprebon, G.; Balzarotti, R.M. New Healthy Settlements Responding to Pandemic Outbreaks: Approaches from (and for) the Global City. Plan J. 2020, 5, 385-406. [CrossRef]

12. Fraenkel, P.; Cho, W.L. Reaching Up, Down, In, and Around: Couple and Family Coping During the Coronavirus Pandemic. Fam. Process 2020, 59, 847-864. [CrossRef] [PubMed]

13. Pratt, A.C. COVID-19 Impacts Cities, Cultures and Societies. CityCult. Soc. 2020, 21, 100341. [CrossRef]

14. Abusaada, H.; Elshater, A. COVID-19 Challenge, Information Technologies, and Smart Cities: Considerations for Well-Being. Int. J. Community Well Being 2020, 1-8. [CrossRef]

15. Capolongo, S.; Rebecchi, A.; Buffoli, M.; Appolloni, L.; Signorelli, C.; Fara, G.M.; D'Alessandro, D. COVID-19 and Cities: From Urban Health Strategies to the Pandemic Challenge. A Decalogue of Public Health Opportunities. Acta Biomed. 2020, 91, 13-22. [CrossRef] [PubMed]

16. Geng, D.C.; Innes, J.; Wu, W.; Wang, G. Impacts of COVID-19 Pandemic on Urban Park Visitation: A Global Analysis. J. Res. 2021, 32, 553-567. [CrossRef]

17. Herman, K.; Drozda, Ł. Green Infrastructure in the Time of Social Distancing: Urban Policy and the Tactical Pandemic Urbanism. Sustainability 2021, 13, 1632. [CrossRef]

18. Hobday, R.A.; Cason, J.W. The Open-Air Treatment of PANDEMIC INFLUENZA. Am. J. Public Health 2009, 99, S236-S242. [CrossRef] [PubMed]

19. Klein, C. How Pandemics Spurred Cities to Make More Green Space for People. Available online: https://www.history.com/ news / cholera-pandemic-new-york-city-london-paris-green-space (accessed on 2 March 2021).

20. Pouso, S.; Borja, Á.; Fleming, L.E.; Gómez-Baggethun, E.; White, M.P.; Uyarra, M.C. Contact with Blue-Green Spaces during the COVID-19 Pandemic Lockdown Beneficial for Mental Health. Sci. Total Environ. 2021, 756, 143984. [CrossRef]

21. Ugolini, F.; Massetti, L.; Calaza-Martínez, P.; Cariñanos, P.; Dobbs, C.; Ostoić, S.K.; Marin, A.M.; Pearlmutter, D.; Saaroni, H.; Šaulienè, I.; et al. Effects of the COVID-19 Pandemic on the Use and Perceptions of Urban Green Space: An International Exploratory Study. Urban For. Urban Green. 2020, 56, 126888. [CrossRef] [PubMed]

22. Shuman, M. Going Local: Creating Self-Reliant Communities in a Global Age; Routledge: New York, NY, USA, 2000; ISBN 978-0-415-92768-0.

23. Oldenburg, P.D.R. The Great Good Place: Cafes, Coffee Shops, Bookstores, Bars, Hair Salons, and Other Hangouts at the Heart of a Community; Marlowe \& Company: New York, NY, USA; Berkeley, CA, USA, 1999; ISBN 978-1-56924-681-8.

24. Pozoukidou, G.; Chatziyiannaki, Z. 15-Minute City: Decomposing the New Urban Planning Eutopia. Sustainability 2021, 13, 928. [CrossRef]

25. Moreno, C.; Allam, Z.; Chabaud, D.; Gall, C.; Pratlong, F. Introducing the "15-Minute City": Sustainability, Resilience and Place Identity in Future Post-Pandemic Cities. Smart Cities 2021, 4, 93-111. [CrossRef]

26. Booi, H.; Boterman, W.R. Changing Patterns in Residential Preferences for Urban or Suburban Living of City Dwellers. J. Hous. Built Environ. 2020, 35, 93-123. [CrossRef]

27. Hasanzadeh, K.; Kyttä, M.; Brown, G. Beyond Housing Preferences: Urban Structure and Actualisation of Residential Area Preferences. Urban Sci. 2019, 3, 21. [CrossRef]

28. Andersson, E.K.; Abramsson, M.; Malmberg, B. Patterns of Changing Residential Preferences during Late Adulthood. Ageing Soc. 2019, 39, 1752-1781. [CrossRef]

29. Bai, Y.; Song, J.; Wu, S.; Wang, W.; Lo, J.T.Y.; Lo, S.M. Comparing the Impacts of Location Attributes on Residents' Preferences and Residential Values in Compact Cities: A Case Study of Hong Kong. Sustainability 2020, 12, 4867. [CrossRef]

30. Jansen, S.J.T. Urban, Suburban or Rural? Understanding Preferences for the Residential Environment. J. Urban. Int. Res. Placemaking Urban Sustain. 2020, 13, 213-235. [CrossRef]

31. Szołtysek, J.; Otręba, R. Attractiveness of Cities during Social Isolation: Views of Residents of the Silesian Voivodeship (Poland). EoR 2020, 16, 1272-1284. [CrossRef]

32. Papadopoulou, C.-A.; Giaoutzi, M. Crowdsourcing as a Tool for Knowledge Acquisition in Spatial Planning. Future Internet 2014, 6, 109-125. [CrossRef]

33. Jankowski, P.; Czepkiewicz, M.; Młodkowski, M.; Zwoliński, Z. Geo-Questionnaire: A Method and Tool for Public Preference Elicitation in Land Use Planning. Trans. GIS 2016, 20, 903-924. [CrossRef]

34. Czepkiewicz, M.; Jankowski, P.; Zwoliński, Z. Geo-Questionnaire: A Spatially Explicit Method for Eliciting Public Preferences, Behavioural Patterns, and Local Knowledge-An Overview. Quaest. Geogr. 2018, 37, 177-190. [CrossRef]

35. Bubalo, M.; van Zanten, B.T.; Verburg, P.H. Crowdsourcing Geo-Information on Landscape Perceptions and Preferences: A Review. Landsc. Urban Plan. 2019, 184, 101-111. [CrossRef]

36. Malczewski, J.; Rinner, C. Multicriteria Decision Analysis in Geographic Information Science; Advances in Geographic Information Science; Springer Berlin Heidelberg: Berlin/Heidelberg, Germany, 2015; ISBN 978-3-540-74756-7.

37. Keeney, R.L. Value-Focused Thinking: A Path to Creative Decision Making; Harvard University Press: Cambridge, MA, USA, 1992; ISBN 978-0-674-93198-5.

38. Malczewski, J. GIS and Multicriteria Decision Analysis; John Wiley \& Sons: New York, NY, USA, 1999; ISBN 978-0-471-32944-2. 
39. Timmermans, H.; Molin, E.; Noortwijk, L. Housing Choice Processes: Stated versus Revealed Modelling Approaches. Neth. J. Hous. Built Environ. 1994, 9, 215-227. [CrossRef]

40. Malczewski, J.; Jankowski, P. Emerging Trends and Research Frontiers in Spatial Multicriteria Analysis. Int. J. Geogr. Inf. Sci. 2020, 34, 1257-1282. [CrossRef]

41. Choo, E.U.; Schoner, B.; Wedley, W.C. Interpretation of Criteria Weights in Multicriteria Decision Making. Comput. Ind. Eng. 1999, 37, 527-541. [CrossRef]

42. Hämäläinen, R.P.; Salo, A.A. The Issue Is Understanding the Weights. J. Multi Criteria Decis. Anal. 1997, 6, 340-343. [CrossRef]

43. Mahmoody Vanolya, N.; Jelokhani-Niaraki, M. The Use of Subjective-Objective Weights in GIS-Based Multi-Criteria Decision Analysis for Flood Hazard Assessment: A Case Study in Mazandaran, Iran. GeoJournal 2021, 86, 379-398. [CrossRef]

44. Fischer, G.W. Range Sensitivity of Attribute Weights in Multiattribute Value Models. Organ. Behav. Hum. Decis. Process. 1995, 62, 252-266. [CrossRef]

45. Bodily, S.E. Modern Decision Making: A Guide to Modelling with Decision Support Systems; McGraw-Hill: New York, NY, USA, 1985; ISBN 0-07-006360-5.

46. Malczewski, J. On the Use of Weighted Linear Combination Method in GIS: Common and Best Practice Approaches. Trans. GIS 2000, 4, 5-22. [CrossRef]

47. Belton, V.; Stewart, T. Multiple Criteria Decision Analysis: An Integrated Approach; Springer Science \& Business Media: Berlin/Heidelberg, Germany, 2002; Second printing; Kluwer Academic Publishers: Dordrecht, The Netherlands, 2003; ISBN 978-0-7923-7505-0.

48. van Delft, A.; Nijkamp, P. Multi-Criteria Analysis and Regional Decision-Making; Studies in applied regional science; Martinus Nijhoff Social Sciences Division: Leiden, The Netherlands, 1977; ISBN 978-90-207-0689-5.

49. Lotfi, F.H.; Fallahnejad, R. Imprecise Shannon's Entropy and Multi Attribute Decision Making. Entropy 2010, 12, 53-62. [CrossRef]

50. Wang, Y.M. A method based on standard and mean deviations for determining the weight coefficients of multiple attributes and its applications. Math. Stat. Manag. 2003, 22, 22-26.

51. Malczewski, J. GIS-based Multicriteria Decision Analysis: A Survey of the Literature. Int. J. Geogr. Inf. Sci. 2006, 20, 703-726. [CrossRef]

52. Malczewski, J. Local Weighted Linear Combination. Trans. GIS 2011, 15, 439-455. [CrossRef]

53. Carter, B.; Rinner, C. Locally Weighted Linear Combination in a Vector Geographic Information System. J. Geogr. Syst. 2014, 16, 343-361. [CrossRef]

54. Ligmann-Zielinska, A.; Jankowski, P. Impact of Proximity-Adjusted Preferences on Rank-Order Stability in Geographical Multicriteria Decision Analysis. J. Geogr. Syst. 2012, 14, 167-187. [CrossRef]

55. Korhonen, P.J.; Silvennoinen, K.; Wallenius, J.; Öörni, A. A Careful Look at the Importance of Criteria and Weights. Ann. Oper. Res. 2013, 211, 565-578. [CrossRef]

56. Veronesi, F.; Schito, J.; Grassi, S.; Raubal, M. Automatic Selection of Weights for GIS-Based Multicriteria Decision Analysis: Site Selection of Transmission Towers as a Case Study. Appl. Geogr. 2017, 83, 78-85. [CrossRef]

57. Kangas, A.; Kangas, J.; Kurttila, M. Decision Support for Forest Management; Managing Forest Ecosystems; Springer Netherlands: Dordrecht, The Netherlands, 2008; Volume 16, ISBN 978-1-4020-6786-0. [CrossRef]

58. Munda, G. Social Multi-Criteria Evaluation for a Sustainable Economy; Springer Berlin Heidelberg: Berlin/Heidelberg, Germany, 2008; ISBN 978-3-540-73702-5.

59. Boroushaki, S.; Malczewski, J. Using the Fuzzy Majority Approach for GIS-Based Multicriteria Group Decision-Making. Comput. Geosci. 2010, 36, 302-312. [CrossRef]

60. Jelokhani-Niaraki, M. Collaborative Spatial Multicriteria Evaluation: A Review and Directions for Future Research. Null 2021, 35, 9-42. [CrossRef]

61. Jankowski, P.; Nyerges, T. GIS for Group Decision Making: Towards a Participatory Geographical Information Science; Taylor and Francis: London, UK, 2001.

62. Danielson, M.; Ekenberg, L. A Robustness Study of State-of-the-Art Surrogate Weights for MCDM. Group Decis. Negot. 2017, 26, 677-691. [CrossRef]

63. Jelokhani-Niaraki, M. Knowledge Sharing in Web-Based Collaborative Multicriteria Spatial Decision Analysis: An OntologyBased Multi-Agent Approach. Comput. Environ. Urban Syst. 2018, 72, 104-123. [CrossRef]

64. Jankowski, P.; Najwer, A.; Zwoliński, Z.; Niesterowicz, J. Geodiversity Assessment with Crowdsourced Data and Spatial Multicriteria Analysis. ISPRS Int. J. Geo Inf. 2020, 9, 716. [CrossRef]

65. Pasi, G.; Yager, R. Modeling the Concept of Majority Opinion in Group Decision Making. Inf. Sci. 2006, 176, 390-414. [CrossRef]

66. Belton, V.; Gear, T. On the Meaning of Relative Importance. J. Multi-Criteria Decis. Anal. 1997, 6, 335-338. [CrossRef]

67. Mahmoody Vanolya, N.; Jelokhani-Niaraki, M.; Toomanian, A. Validation of Spatial Multicriteria Decision Analysis Results Using Public Participation GIS. Appl. Geogr. 2019, 112, 102061. [CrossRef]

68. Youssef, Z.; Alshuwaikhat, H.; Reza, I. Modeling the Modal Shift towards a More Sustainable Transport by Stated Preference in Riyadh, Saudi Arabia. Sustainability 2021, 13, 337. [CrossRef]

69. Saaty, T.L. Decision Making with the Analytic Hierarchy Process. Int. J. Serv. Sci. 2008, 1, 83-98. [CrossRef]

70. Saaty, T.L. How to Make a Decision: The Analytic Hierarchy Process. Interfaces 1994, 24, 19-43. [CrossRef]

71. Saaty, T.L.; Ozdemir, M.S. Why the Magic Number Seven plus or Minus Two. Math. Comput. Model. 2003, 38, 233-244. [CrossRef] 
72. Basak, I.; Saaty, T. Group Decision Making Using the Analytic Hierarchy Process. Math. Comput. Model. 1993, 17, 101-109. [CrossRef]

73. Stillwell, W.G.; Seaver, D.A.; Edwards, W. A Comparison of Weight Approximation Techniques in Multiattribute Utility Decision Making. Organ. Behav. Hum. Perform. 1981, 28, 62-77. [CrossRef]

74. Danielson, M.; Ekenberg, L. Rank Ordering Methods for Multi-Criteria Decisions. In Group Decision and Negotiation; A ProcessOriented View; Springer: Cham, Switzerland, 2014; pp. 128-135.

75. Uribe, D.; Geneletti, D.; Del Castillo, R.F.; Orsi, F. Integrating Stakeholder Preferences and GIS-Based Multicriteria Analysis to Identify Forest Landscape Restoration Priorities. Sustainability 2014, 6, 935-951. [CrossRef]

76. Saari, D.G. The Optimal Ranking Method in the Borda Count. IIASA Collaborative Paper. IISA. 1985. Available online: http:/ / pure.iiasa.ac.at/id/eprint/2744/ (accessed on 6 March 2021).

77. Lee, M.D.; Steyvers, M.; Miller, B. A Cognitive Model for Aggregating People's Rankings. PLoS ONE 2014, 9, e96431. [CrossRef] [PubMed]

78. Milošević, M.R.; Milošević, D.M.; Stanojević, A.D.; Stević, D.M.; Simjanović, D.J. Fuzzy and Interval AHP Approaches in Sustainable Management for the Architectural Heritage in Smart Cities. Mathematics 2021, 9, 304. [CrossRef]

79. Ceballos, B.; Lamata, M.T.; Pelta, D.A. A Comparative Analysis of Multi-Criteria Decision-Making Methods. Prog. Artif. Intell. 2016, 5, 315-322. [CrossRef]

80. Sałabun, W.; Urbaniak, K. A New Coefficient of Rankings Similarity in Decision-Making Problems. In Computational Science—ICCS 2020; Springer: Cham, Switzerland, 2020; pp. 632-645.

81. geoportal.gov.pl. Available online: https://mapy.geoportal.gov.pl/imap/Imgp_2.html (accessed on 12 January 2021).

82. University/Home-Warsaw University of Technology. Available online: https://www.pw.edu.pl/engpw/University (accessed on 3 March 2021).

83. Data on 14-Day Notification Rate of New COVID-19 Cases and Deaths. Available online: https://www.ecdc.europa.eu/en/ publications-data/data-national-14-day-notification-rate-covid-19 (accessed on 7 March 2021).

84. Jaroszewicz, J. Geo-questionnaire as the basis for spatial multi-criteria analysis of housing preferences of students. In Proceedings of the 19th International Multidisciplinary Scientific GeoConference SGEM 2019, Albena, Bulgaria, 30 June-6 July 2019; Volume 19, pp. 855-862, ISBN 978-619-7408-80-5. [CrossRef]

85. Grima, N.; Corcoran, W.; Hill-James, C.; Langton, B.; Sommer, H.; Fisher, B. The Importance of Urban Natural Areas and Urban Ecosystem Services during the COVID-19 Pandemic. PLoS ONE 2020, 15, e0243344. [CrossRef]

86. Dzhambov, A.M.; Lercher, P.; Stoyanov, D.; Petrova, N.; Novakov, S.; Dimitrova, D.D. University Students' Self-Rated Health in Relation to Perceived Acoustic Environment during the COVID-19 Home Quarantine. Int. J. Environ. Res. Public Health 2021, 18, 2538. [CrossRef] [PubMed]

87. Leskinen, P.; Kangas, J. Rank Reversals in Multi-Criteria Decision Analysis with Statistical Modelling of Ratio-Scale Pairwise Comparisons. J. Oper. Res. Soc. 2005, 56, 855-861. [CrossRef]

88. Zahir, S. Normalisation and Rank Reversals in the Additive Analytic Hierarchy Process: A New Analysis. Int. J. Oper. Res. 2009, 4, 446-467. [CrossRef]

89. de Farias Aires, R.F.; Ferreira, L. The rank reversal problem in multi-criteria decision making: A literature review. Pesqui. Oper. 2018, 38, 331-362. [CrossRef]

90. Uehara, M.; Fujii, M.; Kobayashi, K. A Model of Stress Change under the First COVID-19 Pandemic among the General Public in Japanese Major Cities and Rural Areas. Sustainability 2021, 13, 1207. [CrossRef]

91. Alkharabsheh, A.; Moslem, S.; Oubahman, L.; Duleba, S. An Integrated Approach of Multi-Criteria Decision-Making and Grey Theory for Evaluating Urban Public Transportation Systems. Sustainability 2021, 13, 2740. [CrossRef]

92. Balletto, G.; Ladu, M.; Milesi, A.; Borruso, G. A Methodological Approach on Disused Public Properties in the 15-Minute City Perspective. Sustainability 2021, 13, 593. [CrossRef] 